\title{
5. Terminology Currently in Use
}

Makek M: Clinical Pathology of Fibro-Osteo-Cemental Lesions in the Cranio-Facial and Jaw Bones. Basel, Karger, 1983, pp 14-52

Nonossifying Fibroma

Ja.ffe and Lichtenstein's [1942] study is the first to define nonossifying fibroma (variously fibrous cortical defect and metaphy- seal fibrous defect) as a specific pathological entity. These authors classify it as a genuine benign tumor. The lesion occurs almost ex- clusively in children and adolescents, is local- ized in proximity to the epiphyseal area of the lang bones, particulary in the lower limbs, and is most frequently discovered ac- cidentally in the course of radiological exam- inations [Cunningham and Ackerman, 1956). In cases where nonossifying fibroma occurs in a typical location, it is radiologically pa- thognomonic. In most cases of this type, the lesion is situated below the cortex and either a solitary cyst or multiple small cysts are present within the mass, which can measure up to $5 \mathrm{~cm}$ in diameter and is surrounded by a narrow sclerotic border. The condition is characterized by an absence of periosteal reaction and, in many cases, by a thinning of the cortical plate (fig. 4). Classical histologi-

cal definitions distinguish between a fibrous and a xanthomatous form, which can some- times occur simultaneously. The findings ob- tained from conventional microscopic exam- inations suggested that the histogenesis of these lesions had commenced with fibro- blasts. This hypothesis was subsequently confirmed by further examinations using his- tochemical methods and electron microscope 
techniques [Steiner, 1974; Linares et al.,

1978]. Their findings clearly indicated a pro- gressive vacuolization of the fibroblast. Increased presence of lipid-containing foam cells, particularly in the peripheral area, is accompanied by a concomitant lass ofhemo- siderin. In xanthomatous forms of this lesion, the foam cells lose their macrophagic characteristics. In fact, the xanthomatous and fibrous forms of nonossifying fibroma of the bone are nothing other than different phases in the same process, the transforma- tion of fibrocytes into foam cells merely oc- curring at a relatively late stage ofthe lesion's development. These examinations therefore confirm that 'xanthoma' or 'fibroxanthoma' ofthe bone is in factavariant ofnonossifying fibroma of the bone.

The material used for this study [Makek,

1980] covers all relevant cases referred to the Institute of Pathology of the University of Zürich between 1955 and 1978. It considers a total of 160 cases of lesions of this type and constitutes the largest body of statistical data on this subject from the records of one single institute to be published so far (table II). These lesions are most commonly localized in the metaphyseal area of the long bones.

110 of the 160 patients treated were aged between 11 and 20 years.

In recent years, the literature has not de- scribed a single case of nonossifying fibroma of the jaw. Ferguson [1974], for example, states: 'Lesions corresponding to the fibrous

Table II. Nonossifying fibromas (160 cases) exam-

ined at the Institute of Pathology, Zürich, between

1955 and 1978 [from Makek, 1980] 


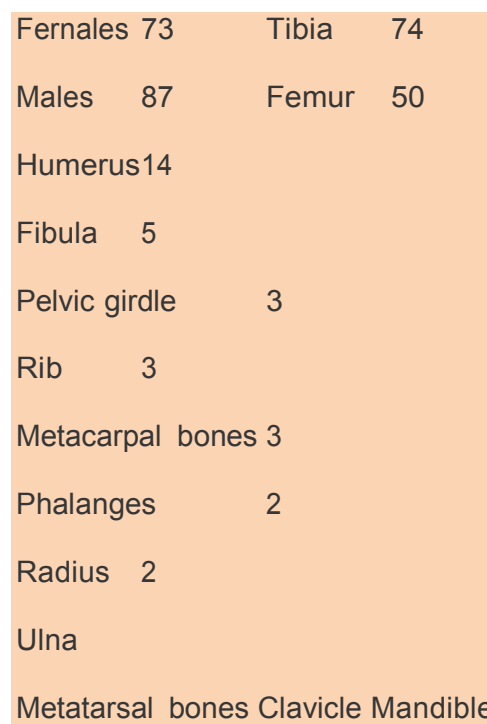

Age distribution

Fig. 4. X-ray of the distal metaphysis of the tibia showing a typical eccentric polycystic lesion. 
Decade $0-10$

n 
$11-20 \quad 21-30 \quad 31-40 \quad 41-50 \quad 51-60$

7

2

3

cortical defect do not appear to have been described in the jaw.' In fact, there is only one case ofnonossifying fibroma ofthe man- dible known to the author; this was a 20-year-old male and was treated by the Zürich University Hospital. The case report [Makek,

1980] states:

'A 20-year-old male was referred to the Maxillo- Facial Surgery Clinic for correction of distocclusion. Besides this developmental deformity there were no other pathologic features, in particular no disturbance in temporamandibular joint function. Routine X-rays revealed the following: the left condylar process showed a polycystic lesion, situated in the lower half of the condylar neck reaching the distal border of the condyle with partial rarefaction of the cortex (fig. 5). Otherwise the grape-like cysts showed distinct mar- 
ginal sclerosis. The differential diagnosis included nonossifying fibroma, myxoma and ameloblastoma. On June 29, 1977, the left condylar process was resected and reconstructed in the same sitting by means of an autologaus rib graft. During the Opera- tion, sagittal splitting of the right ramus was per-formed and the mandible brought into the planned position. The postoperative course was uneventful. The patient was discharged on the 7th postoperative day. Radiological control I year later showed no signs of recurrence.

Macroscopic and microscopic fmdings: The cut

surface displayed both solid gray-white, and soft yel- lowish speckled tissue. The microscopic report read: In the cystic areas the tissue consists of bundles of slender, spindle-shaped cells (fig. 6) with interposed collagen fibers. Nuclei are rather small, round to ovoid, of medium chromatin density. Scattered throughout are polygonal giant cells with 6-8 nuclei and hemosiderin granules. Towards the periphery, the 
Fig. 5. X-ray of the resected left condylar process featuring polycystic lesion [from Makek, 1980 , with permission].

spindie cells give way progressively to foam cells (fig. 7). The original cortical bone is rarefied by widen- ing of the Haversian canals. The area of contact between the bundles of spindle-shaped cells and spongy bone reveals the presence of numerous mono- and multinucleated osteoclasts. The tumor tissue pen- etrates towards the periostium through the Haversian system, without reaching it. The newly formed bone, in part woven, corresponds to the marginal sclerosis seen on X-ray.'

Ossifying fibroma, on the other hand, is common in the maxillofacial bones. Indeed, the incidence of ossifying fibroma in the maxillofacial bones would appear to be in- versely proportional to that in other skeletal areas, where such lesions are veJY rare. This discrepancy is characteristic and deserves 
particular attention. Chapter 7 examines a nurober of further aspects of this question in greater detail.

Since the most common localizations of nonossifying fibromas are situated in growth areas, some authors regard them as localized growth-related disorders and not as genuine tumors [Hatcher, 1945; Cunningham and Ackerman, 1956]. The fact that their localiza- tion is largely restricted to the metaphyseal areas of the long bones suggests that the ini- tial formation of these lesions is in some way connected with the normal transition, during growth, of a given section of a long bone from the metaphyseal to the epiphyseal state. This could also apply to the single case of nonos-

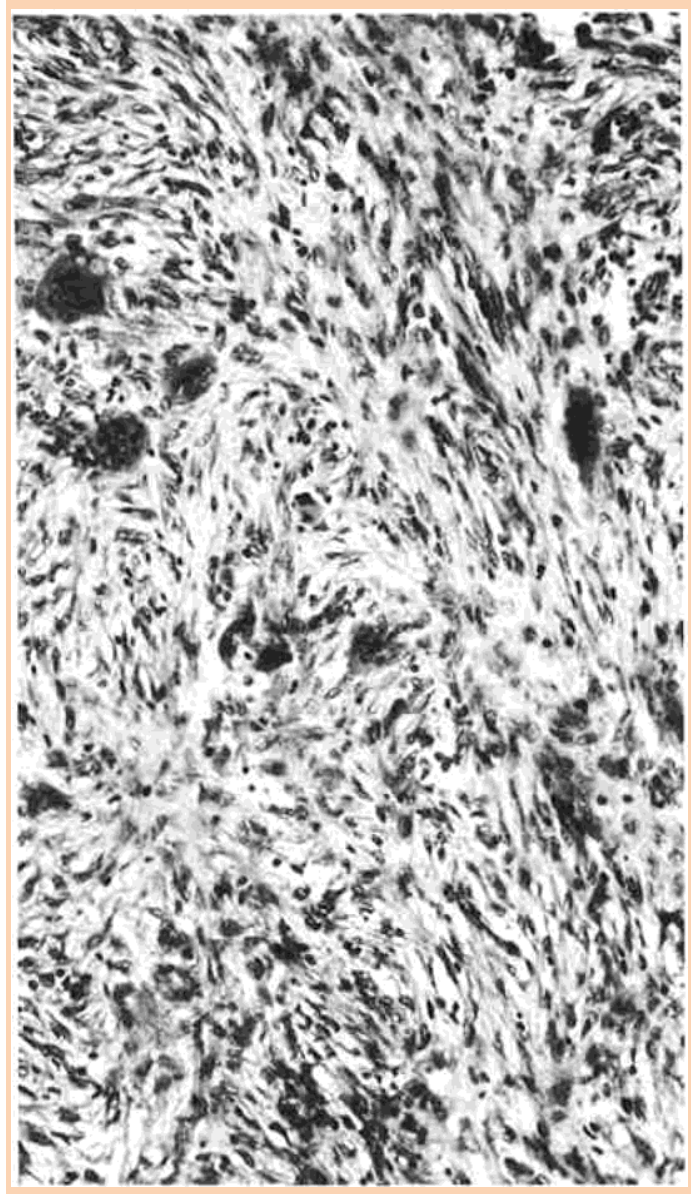


Fig. 6. Nonossifying fibroma ofthe mandible com- posed of whirls of spindle-shaped cells with scattered multinucleated giant cells. HE. $160 \mathrm{X}$.

sifying fibroma of the mandible referred to above [Makek, 1980], since although, strictly speaking, the condylar region ofthe mandible has no metaphysis, nevertheless, during the period of skeletal development, the posterior mandibular condyle does in fact grow, and it does so by apposition of bone. It was pre- cisely in this area that this single lesion re-ferred to above occurred, so that its presence 
Fig. 7. Margin ofthe lesion with !arge areas ofxanthoma cells. HE. $100 \mathrm{X}$.

in what is strictly speaking a nonmetaphyseal area of the skeleton does not necessarily re-fute the tentative hypothesis formulated above to the effect that nonossifying fibroma may be growth related.

'Nonossifying fibromas' arenot characterized by any specific symptoms, a fact which places special constraints on diagnosis and therapy. Should radiological examination

give rise to the slightest doubts about diagno- sis, or in the event of the affected area being so large as to weaken the bone sufficiently for there to be a real danger of spontaneaus frac- ture, curettage or block excision is recom-mended. Should the lesion fail to regress or decrease in size after the completion of skele- tal development, this same therapy is also indicated. Drennan et al. [1974] report rapid healing of fractures induced by nonossifying fibroma treated by wide curettage and packed with adequate bone graft.

Radiological diagnosis guarantees a high degree of accuracy in cases where the lesion is situated in a typical location. When it is localized in a rarer site, histological confir- mation is necessary, even though the lesion may appear to be radiologically characteris- tic. 


\section{Ossifying Fibroma, Fibrous Osteoma (Osteofibroma, Fibro-Osteoma),} Juvenile Ossifying Fibroma and Aggressive Fibrous Dysplasia

Although all the terms quoted have been used in the literature, they have never been clearly and individually defined, nor have the borders between the areas covered by each of them been definitively laid down. As already stated in chapter 2, the term 'ossifying fibro- ma' was first introduced by Montgomery [1927] and has since been accepted as a dis- tinct entity by the majority of the authors [Champion et al., 1949; Svejda and Doman-sky, 1955; Pizer, 1958; Gardner and Hanft, 1960; Reed, 1963; Waldron, 1970; Waldran and Giansanti, 1973b; Dehner, 1973; Gay et al., 1975; Paul et al., 1977; Penneau and Des- nos, 1977; Walter et al., 1979; Carlisle and Hammer, 1979]. 
Sherman and Sternbergh [1948] regard os- sifying fibroma as an essentially monostotic process, occurring exclusively in desmal bones and rarely found anywhere other than in the jawbones. In their opinion, its behav- ior is compatible with that of a benign tumor. A number of authors take radiological find- ings as their main criterion for distinguishing between fibrous dysplasia and ossifying fibroma. They maintain that welldefined le- sions are ossifying fibroma, while poorly de- lineated lesions having a vague transitiona1 zone between the affected area and normal healthy bone tissue are monostotic fibrous dysplasia [Sherman and Sternbergh, 1948; Smith and Zavaleta, 1952; Cooke, 1957; Waldron, 1970; Boysen et al., 1979].

Lautenbach and Dockhorn [1968] see os- sifying fibroma of the jaw as a slow-growing, centrally or peripherally located tumor, which is clearly separated from the healthy bone and presents both opaque and lucent areas when X-rayed. They state that dental tissue is destroyed and the teeth are dis-placed. The main conclusion these authors draw from their histological findings is that ossifying fibroma is characterized by an iso- morphic basic tissue, made up of spindie cells, in which the metaplastic woven bone formations are weil differentiated.

Findborg and Hjorting-Hansen [1974) de-

scribe ossifying fibroma as an encapsulated benign tumor made up of fibrous tissue in which metaplastic bone is eventually pro- duced. These authors regard ossifying fibroma as one of the tumors most frequently occurring in the jawbones and state that it occurs in patients of all ages, though princi- pally in those aged between 30 and 40 . The term 'fibrous osteoma' is particu1arly unwieldy. It has been used to describe lesions both tumoraus [Uyeno, 1909) and dysplastic 
[Phemister and Grimson, 1937]. Even after Lichtenstein and laffe [1942] had introduced the term 'fibrous dysplasia', thus substan- tially reducing the number of cases ascribable to 'fibrous osteoma', the terminology in this area remained unstandardized. This confu- sion is reflected in the varying uses made of the term [Boyko, 1943; Christiansen and Bradley, 1944; Billing and Ringertz, 1946; Maris, 1947; Sonesson, 1950; Budal and Bergen, 1970; Fu and Perzin, 1974]. Billing and Ringertz [1946], for example, reported on 25 cases of a condition they termed 'fibroosteoma' and described as a tumor whose 'basic substance consists of cortical tissue containing clumps of bone tissue and spindie cells'. They distinguish between a relatively frequently encountered type, which they call

'localized fibro-osteoma' and a somewhat rarer variation characterized by 'diffuse bone enlargement'. They draw a further and strict distinction between 'ossifying fibroma' and

'fibro-osteoma', stating that they had found no evidence of the former's being directly related to the skeleton and defining it instead as a metaplastic bone formation occurring in the soft tissue and not in the bone itself. Smith [1965] does not regard fibrous os- teoma as a genuine tumor, but rather as a reaction by thejawbones to some injury, such as tooth extraction, which might have taken place years before. In his view, the essential difference between fibrous osteoma and fibrous dysplasia, which is an active process, lies in the fact that the trabeculae of spon- giosa found in cases of fibrous osteoma are more mature, that fibrous osteoma is some- times characterized by laminated bone for-mation and that it is accompanied by osteoid formation and osteoblasts. He states that fi- brous osteoma can occur in patients of any age, though it is more frequent in adults. 
In cantrast to Smith [1965], Reed and Hagy [1965] describe fibrous osteoma as a well-defined bone lesion most frequently oc- curring in the maxilla or the paranasal cavi- ties. Although the material used for this study shows that the condition can be radiologi- cally identical to monostotic fibrous dyspla- sia, the authors nevertheless believe that it differs from this last histologically in that it presents lamellar bone formation.

Hamner et al. [1968] regard the condition they term fibro-osteoma as another lesion originating in the medullary parts of the bone. They do however agree with Reed and Hagy [1965], insofar as they note that fibro- osteoma is characterized by lamellar bone formation, and they regard this as the feature which distinguishes it from fibrous dysplasia. Lautenbach and Dockhorn [1968] see both fibro-osteoma and osteoid osteoma as special forms of ossifying fibroma of the jaw. They classify fibro-osteoma as a slow-growing be- nign tumor which expands progressively and is characterized by a proliferation of fibrous tissue and lamellar bone formation. They state that the Xray material they used did not always show a clear border between the opaque area representing the tumor and the ordinary bone itself. It is because of this radiological evidence of progressive ossifica- tion that the authors classify the condition as

'fibro-osteoma'. Lautenbach and Dockhorn [1968] also consider the possibility of ossify- ing fibroma of the jaw metamorphosing into fibro-osteoma. The term fibro-osteoma is oc- casionally used as a synonym of ossifying fibroma [Pindborg and Hj@rting-Hansen, 1974]. Though fairlyrarein the literature, the term 'juvenile ossifying fibroma' [Test et al., 
1976; Damjanov et al., 1978] is of consider- able interest. It is also used by Findborg and Hj@rting-Hansen [1974], where it is defined

as a destructive growth process histologically identical to ossifying fibroma. The tumor oc- curs in patients under 15 years of age, is most frequently located in the maxillary area and is clinically characterized by facial asym- metry.

Smith and Zavaleta [1952] described a condition which they termed 'young ossify-ing fibroma' and which merely consisted of spindie cells, osteoblasts and a minimal amount of bone tissue. Their histological de- scription of this condition could weil correspond to the case cited by Pindborg and Hj@rting-Hansen [1974]. Damjanov et al. [1978] also describe juvenile ossifying fi- broma as a locally aggressive tumor prone to recurrence. Its main characteristics, apart from those it has in common with ordinary ossifying fibroma, are given as stroma with a high cell content, in which numerous psam- moma-like bodies and osteobiasts are present. According to Damjanov et al. [1978], juvenile ossifying fibroma produces little bone tissue and the few osseous trabeculae that are present are surrounded by dense layers of osteobiasts. Biopsy material from the center of such tumors is described as consisting aimost exclusively of osteobiasts interspersed with the psammoma-like bod- ies mentioned above. Damjanov et al. [1978] also mention earlier works, based on similar histological findings, in which juvenile ossifying fibroma is classified as psammo-osteoid fibroma as described by Gögl [1949].

Further confusion has been caused by the term 'aggressive fibrous dysplasia', which has been used in such studies as the one by Scho- fleid [1974] to describe lesions which are 
morphoiogically equivaient to the juvenile ossifying fibroma described by Pindborg and HjfJrting-Hansen [1974]. 
Fibrous Dysplasia

(Jaffe-Lichtenstein)

Fibrous dysplasia is a well-defined muta- tion of the osteogenic mesenchyme into an isomorphic spindle-celled stroma containing thinly structured, bizarrely shaped trabeculae of metapiastic woven bone [Uehlinger, 1940; Lichtenstein and Jaffe, 1942]. Many of the spindie cells are grouped together into inter- penetrating bundles or heaps. The small ovoid kernels have a medium Chromatin content, and mitoses are practically never present.

The trabeculae of osseous and fibrous tis- sue which are produced are thin (fig. 8). They are located at aimost regular intervals. Their structures are often hook or horseshoe shaped, though they occasionally form rings too (fig. 9). The fact that in cases of fibrous dysplasia the regular spongiosa is replaced by a structure of fibrous and osseous tissue (fig. 10,11) which is ill suited to expanding and contracting pressures and that the cortex is made narrower as a result of endosteal bone resorption means that the bone itself becomes statically inadequate and is conse- quently subject to fracture or deformation by overstrain.

According to Firat and Stutzman [1968],

fibrous dysplasia accounts for $2.4 \%$ of all tumorous and tumor-like bone lesions. It most frequently occurs in the metaphyseal and diaphyseal areas of the long bones, the shoulder bones, the bones ofthe pelvic girdle and those ofthejaw and skull. The cores tend to occur on one side ofthe skeleton only. The condition is termed either monostotic or po- lyostotic fibrous dyspiasia according to the nurober of bones 
affected. In both cases the initiai clinical symptoms are pains in the affected area of the limbs, deformities and

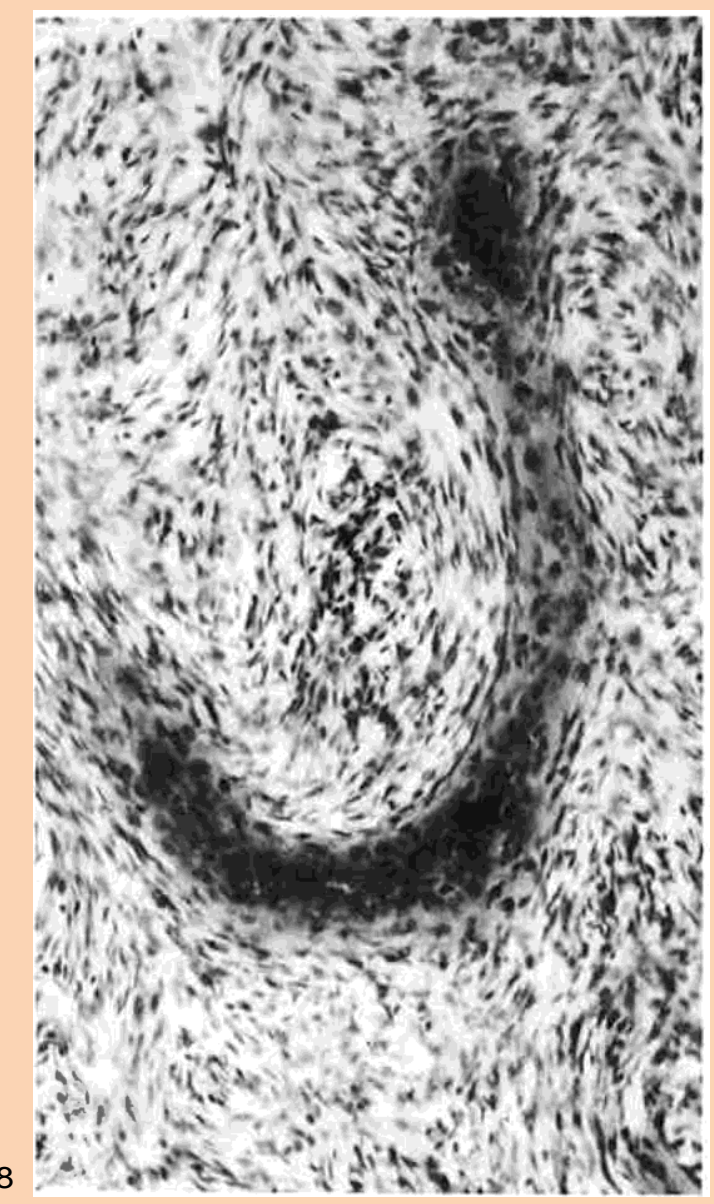

spontaneous fractures, all occurring $\mathrm{m}$ the first 10 years of life. 
McCune-A1bright's syndrome is regarded as a special form of polyostotic fibrous dysplasia. It is normally accompanied by patches of skin pigmentation in the affected area and pubertas praecox. The syndrome has been observed in female patients only. Warrick [1973] compi1ed and eva1uated the following endocrine disorders associated with polyostotic fibrous dysplasia: (1) sexual precocity; (2) accelerated skeletal growth, 


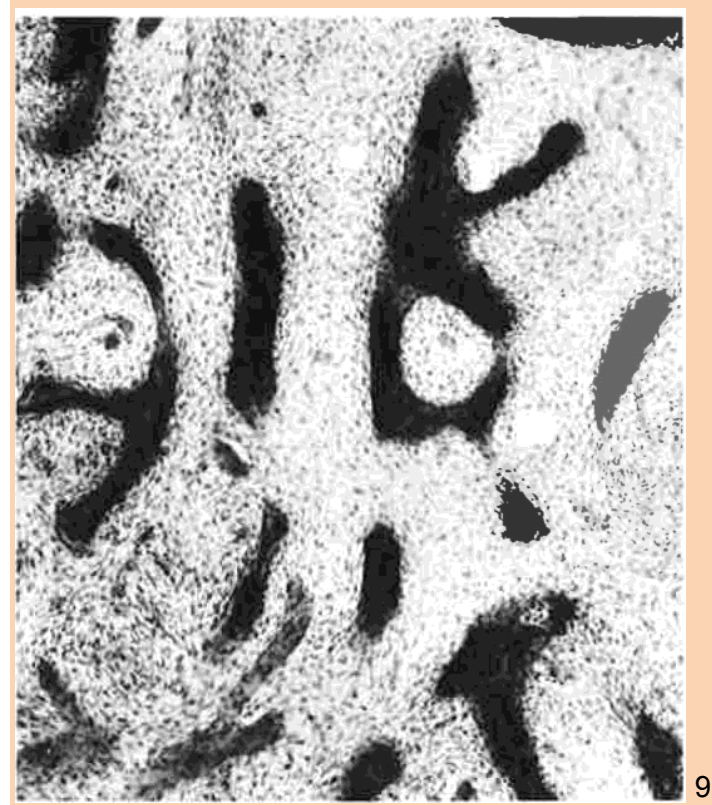

Fig. 8. Fibrous dysplasia. Histological cross-sec- tion showing osteogenic mesenchyme comprising bundles of spindie cells and discrete bone formation. HE. $160 \times$.

Fig. 9. Fibrous dysplasia. The mesenchyme is composed of spindie cells. Note the characteristic metaplastic bone formation. HE. $63 \mathrm{X}$.

normally accompanied by premature fusion ofthe epiphyses; (3) goiter and hyperparathy- roidism; (4) Cushing's syndrome; (5) gyneco- mastia; (6) diabetes mellitus 
(extrainsular hy- pothalamic form); (7) acromegaly, and (8) hyperparathyroidism

(caused by adenoma of the parathyroid g1and [Firat and Stutzman, 1968] or hyperplasia ofthe parathyroid g1and

[Benedict, 1962].

Despite the histological characteristics which the two conditions share, from a clini- cal point of view, fibrous dysplasia in its
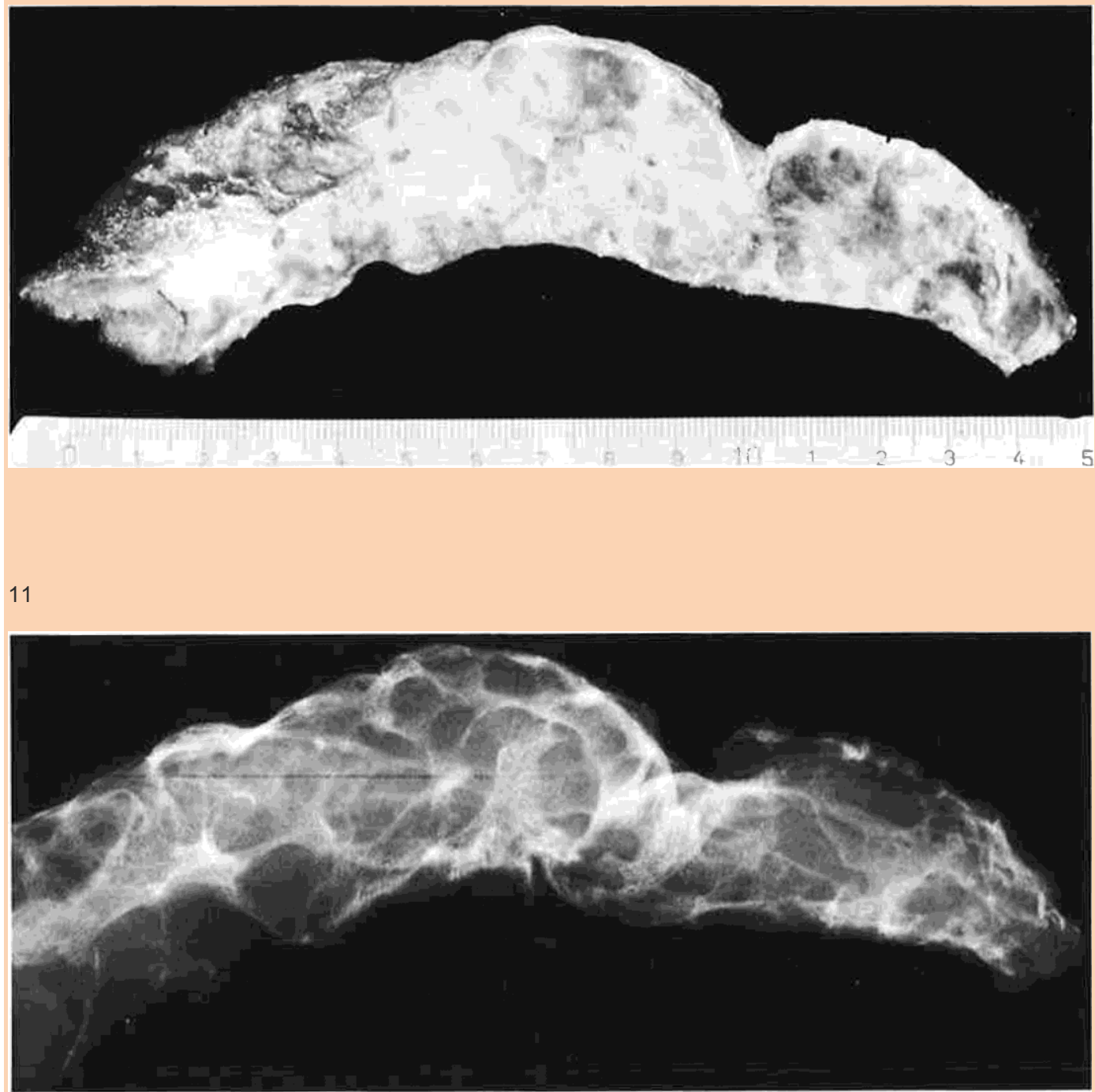
Fig.IO. Classic example offibrous dysplasia ofthe ribs. The cortex is heavily attenuated and the cut surface homogeneaus and grayish-white in color.

Fig.II. X-ray ofthe resected rib from the lesion depicted in figure 10. Note the polycyclic zone ofcystoid radiolucency [from Makek 1977, with permission].

polyostotic form differs from the monostotic variety in a number of ways, namely: (1) in the fact that it can occur in the shoulder and pelvic girdle, spine, skull and jaws; (2) in its tendency to affect entire limbs (i.e. arm and shoulder-girdle, leg and pelvic girdle); (3) in its tendency to affect one side ofthe skeleton only, so that the skeleton appears tobe com-posed of two incompatible halves joined 
along the middle; (4) in the greater incidence of deformity or even crippling, particularly in the long bones. The femur, for example, is sometimes distorted into a shape resembling that of a shepherd's crook, and (5) in the rel- atively high incidence of spontaneaus frac- tures.

Clinically speaking, monostotic fibrous dysplasia should not be regarded as an early

Table 111. Fibrous dysp1asia of the mandib1e and maxilla

Author(s)Year 
Number Lesion 1oca1ized in of cases

considered mandible maxilla both bones

\section{Zimmerman et al.}

\section{8}

69

40

28

Hauston

1965

8

5

3

Henry

1969

12

6

6

Dah/gren et al.

1969

20

4

16

Gibsan and Middlemiss

1971

9

4

5

Waldran and Giansanti

$1973 a$ 
9

Total

$(49 \%) \quad(51 \%)$

phase or forerunner of polyostotic fibrous dysplasia, and each has therefore been classi- fied as a separate pathological entity in itself [Schlumberger, 1946b; Gibsan and Middle- miss, 1971; Hall and Warrick, 1972].

Generally speaking, cases of fibrous dys- plasia in the maxillo-facial bones tend to be monostotic. When it does occur in its polyos- totic form, fibrous dysplasia is accompanied, in $40-50 \%$ of cases, by a lesion in the base of the skull or in some other maxillo-facial structure [Harris et al., 1962]. Most pa- tients who are sufl'ering from a single lesion of fibrous dysplasia are less than 20 years of age when the condition is diagnosed, and some authors state that there are twice as many female patients in this category as male [Eversole et al., 1972; Dehner, 1973].

22 of the cases described by Waldron and Giansanti [1973a] do not correspond to these criteria. 
Table III considers 140 cases of fibrous dysplasia drawn from the literature and shows that in $49 \%$ ofthe cases the lesion was located in the mandible, which makes it al- most as frequently affected as the maxilla 
(including the base of the orbits and the antrum). Sherman and Glauser [1958], on the other band, state that fibrous dysplasia occurs twice as frequently in the mandible as in the maxilla.

The principal characteristics of fibrous dysplasia in the cranial bones are headaches (particularly when the orbits are affected), sporadic bouts of partial or totallass of con-sciousness and impaired sight and hearing. When the ethmoid bone or the horizontal table of the frontal bone are affected, the lesion normally occurs on one side only and causes a narrowing and displacement of the orbital cavity. Where one orbital cavity only is affected, the patient presents a grotesque facial expression. The process can spread to the nasal and paranasal cavities and lead to respiratory impediments. Radiologically, fi- brous dysplasia ofthe jaw typically presents a lesion without clearly defined borders which does not encroach upon the periapical dental area. The peripheral areas of the lesion often blend so smoothly into the normal bone tis- sue, that it is often difficult to see exactly where the lesion ends. The transitional zone 


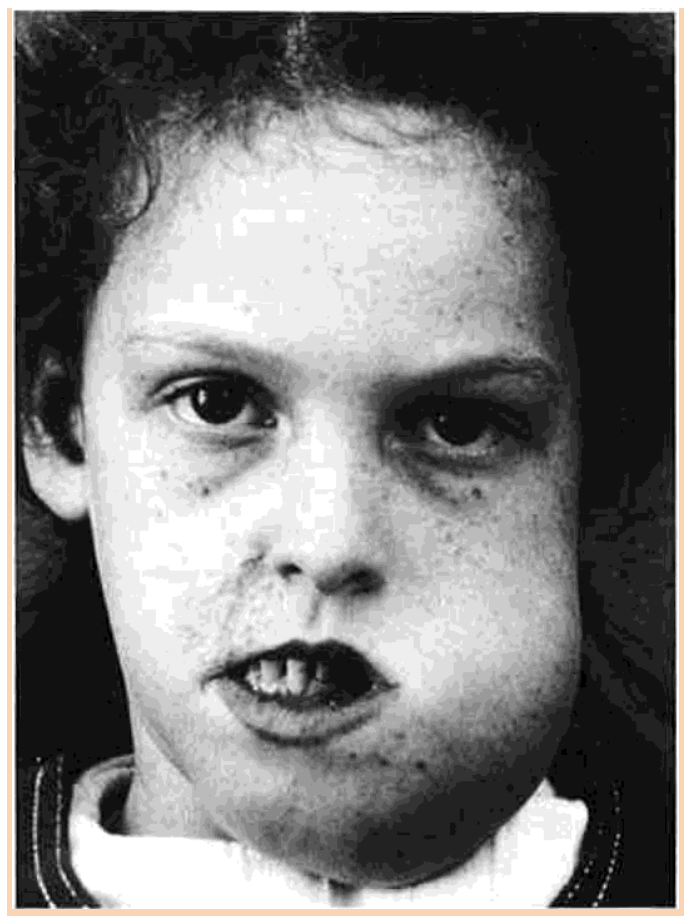

Fig. 12. Grotesque deformation ofthe mandible in a case of polyostotic fibrous dysplasia (6-year-old female patient) (courtesy of Prof. J. Wel/auer, Zü- rich).

between the affected and healthy areas can have a width of one or more centimeters [Waldron and Giansanti, 1973a].

A typical case of fibrous dysplasia (fig. 12,

13) presents a very homogeneaus radiological picture, and its appearance has in fact been likened to that of ground glass. Mixed le- sions, parts of which are radiodense while others are radiolucent or dotted with cystic areas, arealso often encountered. It is rare to find the process in a multifocal or densely sclerotic form. According to Fries [1957], there are three radiologically distinct forms of fibrous dysplasia occurring in the maxillo- facial area: 
Fig. 13. Mandibular X-ray of the patient depicted in figure 12. The lesion is visible as an area ofintense radiodensity in the region of the mandible.

(1) The pagetoid type: it is characteristic of this type oflesion that the skull expands outwards, thus thinning, inflating, buckling and displacing the outer horizontal table of the frontal bone. The sphenoid bone is often affected in the same way. The inner table is substantially expanded and denser and there are numerous points at which it becomes loosened from the bone surrounding it.

(2) The sclerotic type: this type consists of a massive thickening of the entire base of the skull including the orbital region. This scle- rotic type of fibrous dysplasia appears as a horizontal plate located along the lower rim of the orbital cavity. It is poorly delineated,

has a high calcium content and can be up to $2 \mathrm{~cm}$ in width.

(3) The cyst-like type: these are oval or rosette-shaped lesions, of $2-5 \mathrm{~cm}$ in diameter, surrounded by a thin sclerotic border. In cases where there is a single core, the lesion is similar in appearance to eosinophilic granu- loma. When multifocal, the lesion resembles a Hand-Schüller-Christian condition.

Obwegeser et al. [1973] submit a total of nine observed cases to illustrate the remark- able extent to which the clinical and radiolog- ical characteristics of fibrous dysplasia can vary when the lesion is located in the bones ofthe jaw and skull. Basing their conclusions on a consideration of the 
corrective surgical treatment administered in each of these cases, these authors suggest that fibrous dys- plasia in the cranio-facial area should be clas- sified as follows: (a) monostotic, restricted polyostotic, and generalized; (b) a juvenile form which is arrested or which regresses at puberty, and a persistent form, and (c) a solid and a cystic form.

Unlike monostotic fibrous dysplasia, fi- brous dysplasia in its polyostotic form can be radiologically diagnosed with complete cer- tainty. The distortion of the femur into a shape similar to that of a shepherd's crook is pathognomonic. As far as morphology and localization are concerned, the radiological picture presented by bones affected by Al- bright's syndrome is similar to that seen in cases of polyostotic fibrous dysplasia without endocrine disturbance. Radiological diagno- sis of monostotic fibrous dysplasia requires confirmation by biopsy.

From a prognostic point of view, fibrous dysplasia does not constitute a direct threat to life, and monostotic masses require no treatment, provided they are causing no functional disturbance. A corrective recon- 
touring osteotomy should be performed where necessary. If spontaneaus fracturcs oc- cur, resection and immediate reconstruction with material from the ribs or pelvic girdle is advisable. Surgical intervention should only take place once the bones concerned have completed their growth period [Uehlinger, pers. commun., 1979]. There has been considerable discussion of the possibility of recurrence in cases of fi- brous dysplasia. The real difficulty here is that since it is not normally possible to excise these lesions completely, the genuineness of what appear tobe recurrences is very difficult to assess. Zimmerman et al. [1958] lay par- ticular emphasis on this point, and they con- sider it more appropriate to define such lesions as 'persistent'. Their case material showed that in $19 \%$ of the cases of fibrous dysplasia ofthejaw, the condition was in fact persistent, and that in such cases the lesion had normally expanded again within 2 or 3 years of the first surgical intervention. As these authors point out, one of the main rea- sons for the relatively high incidence of persistent fibrous dysplasia is the fact that the lesion is poorly delineated, so that when the condition is treated surgically, it is often not possible to remove the dysplastic bone in its entirety.

Because of the possibility of sarcomatous transformation of the dysplastic area, it is advisable that fibrous dysplasia be subjected to indefinite routine examination. The first report to draw attention to sarcomatous mutation in fibrous dysplasia was by Coley and Stewart [1945], and cited 2 cases. Schwartz and Alpert [1964] were able to com- pile a total of 28 cases, and Huvos et al. [1972] reported on 12 further cases. In a minority of these cases, sarcomatous trans- formation could conceivably be imputed to 
exposure to X-rays. Schwartz and Alpert [19641 estimate the incidence ofsarcomatous mutation in cases of fibrous dysplasia at

$0.5 \%$ of all cases, which would make it four times as rare as sarcomatous mutation in Paget's disease.

\section{Cemental Lesions}

The first significant works to study and define 'cementoma' as an entity are undoubtedly those by Rywkind [19301, Stafne [1933, 19341, Thoma [19371, Bernier and Thompson [19461, Findborg [19511 and Ze-garelli and Kutscher[19611. Extensive epide- miological studies were published by Stafne [19331, Zegarelli and Kutscher [19611 and Zegarelli et al. [19641. A review ofthe litera- ture pertaining to cemental lesions shows that, until they were classified by the WHO in 1971, a very wide range of differing terms bad been used to define them. Just how con- fused the terminology had become can be seen in the following examp1es: 'periapical fibrous dysplasia' [Chaudry et al., 1958; Lustman et al., 19781, 'periapical osteofibro- sis' [Stafne, 1934], 'periapical fibro-osteo- cementoma' [Morgan and Morgan, 1968], 'ossifying periapical fibroma' [Ennis and

Berry, 19481, 'periapical fibroma' [Stafne, 19431, 'periapical fibro-osteoma' [Fontaine, 19551. Findborg and Kramer's [19711 WHO classification eliminates the majority ofthese terms and defines cementoma as a generic term covering four distinct entities, namely: (1) periapica1 cemental dysplasia (a term which is synonymaus 
with periapical fibrous dysplasia); (2) cementifying fibroma; (3) be- nign cementoblastoma (genuine cemento- ma), and (4) gigantiform cementoma (famil- ial, multiple cementoma). 
The results obtained by the present study are based on a compilation and evaluation of all the cases of benign cementoblastoma de- scribed in the available literature.

Since there are a number of respects in which these results do not correspond with the WHO classification, a brief description of the four forms seems in order.

Periapical Cemental Dysplasia (Also

Termed Periapical Fibrous Dysplasia)

Periapical cemental dysplasia is most often discovered accidentally during X-ray examinations performed for some other pur- pose. Clinical symptoms are extremely rare. The affected teeth always respond positively when subjected to snow vitality tests, a fea- ture which conclusively distinguishes this condition from apical, cystic and inflamma- tory processes. The lesion most commonly occurs in middle-aged female patients and is localized at the front of the mandible in the majority of cases. Stafne [19341 and Zegarelli et al. [19641 put the incidence of diagnosed lesions of this type at 2 or 3 cases/1,000 patients. According to Thoma [1937], lesions of this type typically have three distinct stages of development: an osteolytic stage; a cementoblastic stage, and a mature, inactive stage.

Osteolytic Stage. In this first stage, hone is replaced by fibroblasts and collagenaus fibers. On X-ray, the affected area shows up as a spherical apical area of radiolucency. 
Cementoblastic Stage. When X-rayed, the area around the tip ofthe tooth roots presents both radiodense and radiolucent zones (fig.

14). Asthis second stage progresses, the iso-

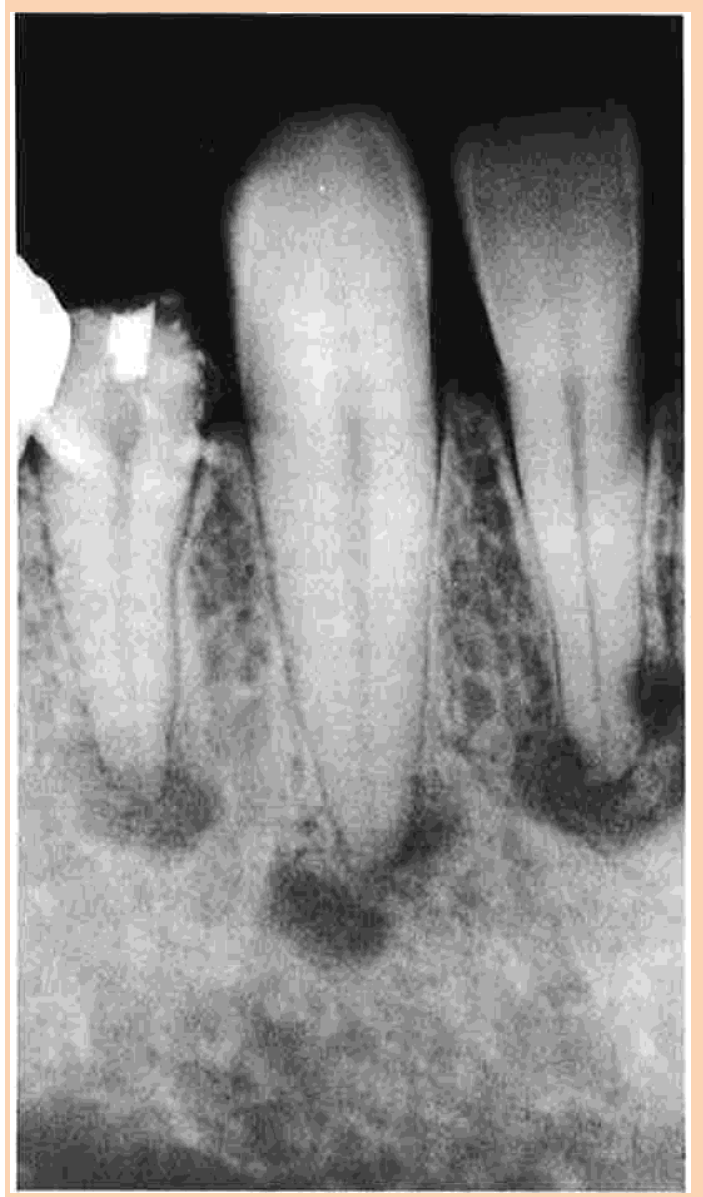

Fig. 14. Periapical cemental dysplasia. The front of the mandible contains multiple lesions at various stages of development (48-year-old female patient). 
lated zones of radiodensity join tagether at the center. Once this begins to occur, the areas of radiolucency cease to expand. Initially, cal- cifying woven tissue is frequently found in the center [Zegarelli et al., 1964], though it is rarely present in the peripheral area [Fontaine,

1955]. Spherical cementicles are formed which gradually expand and fuse into large masses of solid cementum (fig. 15). These 
Fig.15. Histological cross-section of a periapical cemental dysplasia lesion. The stroma is loose, and layered mineralized structures are present in some areas. HE. $160 \mathrm{X}$.

characteristics can be very similar to those presented by fibrous dysplasia of the bone [Findborg and Hjerting-Hansen, 1974].

Mature, Inactive Stage. Radiological ex- amination of the lesion in its third stage of development reveals compact masses of ra- diodensity, shaped like drops of water and surrounded by a translucent border. It is this

Tableiv. Benign cementoblastoma: cases re-Cementifying Fibroma viewed

Cementifying fibroma is a painless tumor occurring in middle-aged patients and most frequently localized in the molars and premo- lars of the mandible [Pindborg and Kramer,

1971]. Its pathological and clinical character- istics have not yet been defined with very great clarity. The lesion can cause bone en- largement. Its radiological characteristics de- pend on how far advanced the condition is: in its initial stage, it presents a welldefined area of radiolucency which becomes increas- ingly calcified and difficult to define as the tumor progresses [Hamner et al., 1968]. The condition's histological characteristics also change as it develops. In its early stage, it presents fibrous tissue with a very high con- centration of fibrob1ast-like cells, while in later phases, interfused spherica1 cementicles with a low cell content are found. 


\section{Benign Cementoblastoma}

Benign cementob1astoma is a little known, extremely rare, benign odontogenic tumor of mesenchymal origin. Findborg and Kramer's [1971] WHO classification defines it as a genuine neoplasm, characterized by the for- mation of 1eaves of cementum-1ike tissue. According to the WHO classification, benign cementoblastoma has the following charac- teristic features: a central area ofradiodensity surrounded by a thin border of radiolucency;

translucent border which distinguishes peri- and a direct bond between the tumor and the apical cemental dysplasia from osteosclerotic root ofa premo1ar or molar ofthe mandible. processes of inflammatory origin. Histologi- The available literature presents a total of no cal examination of the lesion at this stage of more than 33 cases. A further case is pre- development reveals the presence of almost sented by a patient receiving treatment at our acellular cementum-like masses presenting clinic [Makek and Lello, 1982]. A number of thick, jagged 1ines of cementum. cases, which bad been classified as benign 
Fig.16. Benign cemento- blastoma in a 19-year-old male patient. Orthopantomogram presenting typical characteristics [from Makek and Lello, 1982, with permission].

cementoblastoma by other authors, could unfortunately not be used for the present study, either because they were insufficiently documented or because they did not conform to WHO criteria [Thoma, 1937; Pindborg, 1951; Gor/in et al., 1961; Freidei and Gon- non, 1962]. Table IV gives details of all the cases of benign cementoblastoma so far de-scribed. The evidence shows that benign cementoblastoma is characterized by the following features:

(1) The tumor has a specific radiological appearance, clearly distinct from that of other lesions, thus facilitating differential diagnosis (fig. 16). 29 of the cases described presented the typical radiological characteris- tics of a central, mosaic-like area of radioden- sity incorporating the tooth roots and sur- rounded by a thin, well-defined 
radiolucent border. There were only 2 cases which did not present these radiological characteristics. 
In all the cases the border between the lesion and the surrounding bone is weil defined. Radiologically, the structure ofthe woven tis- sue appears to be subject to great fluctua- tions. The descriptions in the various cases range from 'very dense' to 'densely granu- lous', 'spotted', 'irregularly calcified' and 'mosaic-like'. In 16 of the cases, the area of radiodensity can be described as hetero- geneaus and in 6 cases as homogeneous. Root resorption was observed in 13 cases. The other authors give no details on this point.

(2) The tumor very often appears to be accompanied by swelling and other more or less painful symptoms. Only 4 ofthe 34 cases were totally symptomless. Of the other cases where the relevant data is given, 2 were accompanied by pain only and 8 by swelling only, while pain and swelling together were reported in 17 cases. 
Fig. 17. Benign cementoblastoma. Fragment of a tooth root with which tumor tissue is in contact. HE.

$40 X$

Fig. 18. Benign cementoblastoma. The tumor mass is practically acellular and has recognizable, broad rever-

sallines. HE. $40 X$. 
Fig. 19. Benign cemento- blastoma. Histological cross- section taken from a well-vascu- larized area of the tumor where the cell density is high and accu- mulations of cementoblasts are present. HE. $320 \mathrm{X}$.

(3) Incidence of the tumor is equally dis- tributed between the sexes. In cantrast to the findings of other studies [Cherrick et al., 1974; Corio et al., 1976], the present study indicates that one of the characteristics of benign cementob1astoma is that it occurs with equal frequency in patients of either sex. Ofthe 34 cases shown in table IV, 17 occur in female patients and 17 in males.

(4) The age distribution ofthe patients in whom the tumor occurs is also characteristic. The average age ofthe 34 patients considered is 19.7 years, which clearly differentiates it from periapical cemental dysplasia, a condi- tion occurring predominantly in female pa- tients aged between 30 and 49 . 
(5) The fact that the tumor is predomi- nantly localized in the molar region is also characteristic. $77 \%$ of the tumors considered in the present study are localized in the molar region ofthe mandible, and $23 \%$ in the molar 
region of the maxilla. The fact that in $52 \%$ of the cases considered, the lesion is localized in the first molars of the mandible is particu- larly remarkable.

Histological evidence also shows that it is typical for the tumor to be fused with the tooth root (fig. 17). Biopsy material obtained from the central areas of mature tumors shows them to be homogeneous. In mature tumors, the central area consists of cemen- tum-like material with a low cell content punctuated by dense undulating seams (fig.

18). Large conglomerations of cementoblasts are found in the peripheral areas which are still active (fig. 19). In 14 cases, microscopic examination revealed the presence of a ti- braus capsule. Six authors state categorically that no fibrous capsule is present, while seven have nothing to say on this point. As far as therapy is concerned, complete agreement apparently prevails. In all 34 cases the tumor 
Fig. 20. 15-year-old female patient whose Jeft maxilla has been distended by a clearly visi- ble finely grained osseous struc- ture (in 1971 a histological diag- nosis of isolated dystrophy of the jaw was returned).

was enucleated and the affected teeth were extracted. There was no evidence of recurrence in any of the cases, and enucleation of the tumor can therefore be regarded as the therapy of choice.

\section{Gigantiform Cementoma}

The WHO classifications define giganti- form cementoma as a mass of dense, high1y calcified, quasi-acellu1ar cementum often oc- curring simultaneous $1 \mathrm{y}$ in a number of differ- ent 1 ocalizations in the jaws. An e1ement of congenita1ity cannot be ru1ed out, since the cases by Agazzi and Belloni [1953], Bixler [1976] and Cannon et al. [1980] all include severa1 members ofthe same fami1y suffering from 1esions of this same type. Bixler [1976] concludes from this that gigantiform cemen- 
toma might be characterized by autosoma1- dominant congenita1ity. The tumor's main mass consists of basophi1ic, concentrically 1ayered acellu1ar masses which are on1y sparsely vascu1arized. One radio1ogical char- acteristic of gigantiform cementoma which distinguishes it from cementoblastoma is the fact that it has radio1ucent borders. C1inica1 observation shows that giganti- form cementoma experiences its most rapid growth in patients aged between 10 and 29. Surgica1 intervention is on1y advisab1e in cases of severe facia1 deformity or when the 1esion is so densely calcified that it is no lon- ger sufficiently vascu1arized and becomes subject to secondary infection. Cannon et al. [1980], reporting on 2 cases of gigantiform cementoma (in a fema1e patient and her son), state: 'Results ofrecontouring for aesthetic or prosth((tic reasons may be disappointing be- cause the tumor may recur.' 
Fig. 21. Cross-section giving

a general histological view ofthe lesion depicted in figure 20. The bone formations have a pro- nounced lamellar structure, and present numerous lacunae where resorption has occurred. The stroma has a high cell content and the reversal lines are often broken off. HE. $100 \mathrm{X}$.

Isolated Dystrophy of the Jaw (Lautenbach-Dockhorn)

Lautenbach and Dockhorn [1968] de- scribe a special form of Lichtenstein and Jaffe's [1942] fibrous dysplasia, which occurs in the jawbones and which they term 'isolated dystrophy of the jaw'. For this study, the authors have compiled and evaluated a total of 34 cases of this type. Their clinical observations show that the lesion can grow in one of two ways. One form of growth is char- acterized by slow, continuous and almost symptom-free development which eventu- ally ceases to progress. The other is intermit- tent and accompanied by sporadic bouts of pain and swelling; subfebrile temperatures and swelling of the regionallymph nodes are also common in cases of this second type. Despite these symptoms, these authors do not believe that the condition is of inflamma- 
tory ongm. Radiological examination also shows that there are two types of 'isolated dystrophy of the jaw' - a hypostotic form where cyst-like areas of radiolucency predominate, and a hyperostotic form featuring bone enlargement and radiodensity. These authors also mention that these two forms in fact constitute extremes between which al- most infinite variations are possible. The in- traoral X-rays show structures similar in ap- pearance to ground glass (fig. 20), presenting patterns comparable to a fingerprint. Their histological examinations led them to the conclusion that isolated fibrous dysplasia of the jaw consists of a basic tissue of woven material. This fibrous tissue differs from that found in cases of fibrous dysplasia of the jaw in other localizations in that the trabeculae of bone are thicker (fig. 21). They go on to state that in cases of isolated fibrous dysplasia in its hypostotic form the biopsy material is

Tab1e V. Summary of published cases of desmop1astic fibroma in the jawbones

Case Author(s)Year Age Sex Loca1ization

\begin{tabular}{lllllll} 
Burch and Woodward & 1960 & 14 & $\mathrm{f}$ & \multicolumn{2}{l}{ mandib1e } \\
2 & Haym 1960 & 5 & $\mathrm{~m}$ & mandible & \\
3 & Griffith and Irby & 1965 & 8 & $\mathrm{f}$ & mandib1e \\
4 & Marlette and Gerhard & 1968 & 21 & $\mathrm{~m}$ & mandib1e \\
5 & Rabhan and Rosai & 1968 & 13 & $\mathrm{~m}$ & mandib1e \\
6 & Hinds et al. & 1969 & 15 & $\mathrm{~m}$ & mandib1e \\
7 & Gosserez et al. 1970 & $\mathrm{I}$ & $\mathrm{f}$ & mandible \\
8 & Bear 1973 & 26 & $\mathrm{f}$ & mandible & \\
9 & Dehner 1973 & 13 & $\mathrm{~m}$ & mandible & \\
10 & Dehner 1973 & 13 & $\mathrm{~m}$ & mandible & mandib1e \\
II & Hovinga and Ingenhoes & 1974 & 14 & $\mathrm{f}$
\end{tabular}




\begin{tabular}{|c|c|c|c|c|c|c|}
\hline 12 & \multicolumn{3}{|c|}{ Findborg and Hjerting-Hansen } & 1974 & 2 & $\mathrm{~m}$ \\
\hline 13 & Bullens et al. & 1975 & \multicolumn{2}{|c|}{15 months } & $\mathrm{m}$ & mandible \\
\hline 14 & \multicolumn{2}{|c|}{ Calatrava and Donado } & 1975 & 2 & $\mathrm{f}$ & mandible \\
\hline 15 & \multicolumn{2}{|c|}{ Cunningham et al. 1975} & 4 & $\mathrm{~m}$ & \multicolumn{2}{|c|}{ mandible } \\
\hline 16 & Rauchan et al. & 1975 & 39 & f & \multicolumn{2}{|c|}{ mandible } \\
\hline 17 & \multicolumn{2}{|c|}{ Fisker and Phifipsen } & 1976 & 27 & f & mandib1e \\
\hline 18 & Nussbaum et al. & 1976 & 3 & $f$ & \multicolumn{2}{|c|}{ mandible } \\
\hline 19 & Wagner et al. & 1977 & 25 & $\mathrm{~m}$ & \multicolumn{2}{|c|}{ mandible } \\
\hline 20 & Freedman et al. & 1978 & 26 & $f$ & \multicolumn{2}{|c|}{ mandib1e } \\
\hline 21 & Lagace et al. & 1979 & 3 & $f$ & \multicolumn{2}{|c|}{ mandib1e } \\
\hline 22 & \multicolumn{2}{|c|}{ Taguchi and Kaneda } & 1980 & 27 & f & mandib1e \\
\hline 23 & Case I Zürich & 15 & $\mathrm{~m}$ & \multicolumn{3}{|c|}{ mandible } \\
\hline 24 & Case 2 Zürich & 33 & $f$ & \multicolumn{3}{|c|}{ mandible } \\
\hline 25 & Case 3 Zürich & 21J2 & $\mathrm{m}$ & \multicolumn{3}{|c|}{ mandible } \\
\hline
\end{tabular}

dominated by a basic structure of fibrous material, whereas in the hyperostotic form woven bone predominates. Their Observa- tions showed that the condition did not occur in patients aged less than 10 years. The ma-jority of cases occurred in female patients aged between 10 and 19 years.

Desmop1astic Fibroma

Desmaid tumors are rare. Of a total of 
5,346 tumors covered in a study by Pack and

Ehrlich [1944], on1y 17 (0.3\%) were desmoid. 
A study carried out by Dahn et al. [1963]

concludes that they had an incidence of

$2 /$ million of the Swedish population/year. In addition to being difficult to diagnose clinically, it is a lesion whose surgical treatment, because of the infrequency with which the condition occurs, has not been widely dis- cussed. Das Gupta et al. [1969] state that it is most frequently located in the anterior ab- dominal wall.

In recent years, the classification of des- moids has undergone complete change. As more information became available, the ini- tial view that they were neoplasms [Meurers,

1951; Geschickterand Lewis, 1953; Dominok and Knoch, 1967] was gradually revised. A1- though, histo1ogically speaking, they appear benign, and despite the fact that no metas- tases have been reported, their locally inva- sive behavior and the characteristically high recurrence rate have induced some authors to classify them as 'semimalignant' [Uehlinger, pers. commun., 1979].

laffe [1958] was the first to pub1ish a description of the lesion occurring in hone. He drew attention to certain similarities be- tween soft tissue desmoid and his own case material, which covered cases occurring in hone. His findings were supported by those of Rabhan and Rosai [1968], who concluded, in the light ofthe clinical and histological evi- dence available, that a condition they termed

'osseous desmoplastic fibroma' was the os-

seous counterpart of the desmoid tumor found in soft tissue. It wou1d perhaps be more appropriate to classify the condition as an osseous form of fibromatosis, a 
definition favored by an increasing nurober of authors [Gonatas, 1961; Rabhan and Rosai, 1968; Ackerman and Rosai, 1974; Werner and Schröter, 1974; Freedman et al., 1978].

The task of compi1ing accurate data on

desmoplastic fibroma is made particular1y difficu1t by the fact that little is known about its pathogenesis and that it can often be con- fused histo1ogically with low-grade hone fibro- sarcoma. Table $V$ gives details ofall pub1ished cases of desmoplastic fibroma occurring in the jaw region and appends three further cases from the records of the C1inic for Max- illo-Facial Surgery of the Zürich University Hospital.

Illustrative case: In May 1957, a 2 h-year-old boy was admitted suffering from extensive swelling of the right cheek. At the time, the swelling had been present 


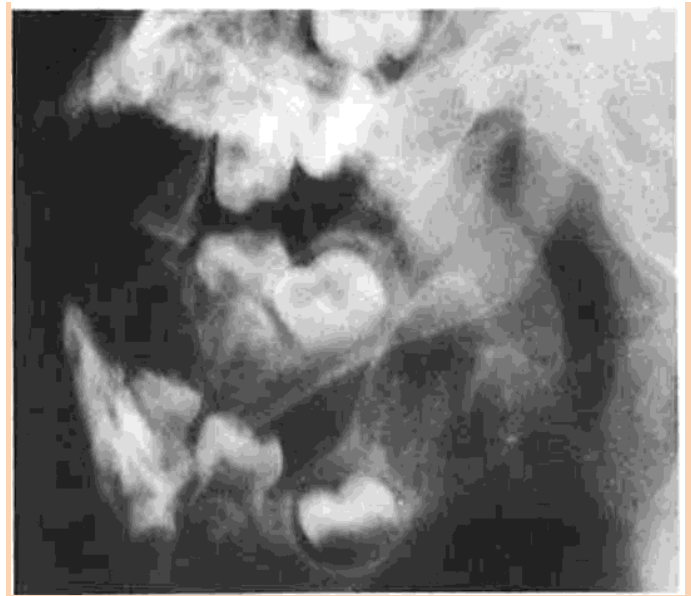

Fig. 22. Lateral oblique $\mathrm{X}$-ray ofthe right mandib- ular angle and ramus, showing multilocular areas of radiolucency surrounded by narrow radiopaque bor- ders.

for some 18 months, and had increased progressively in size. There were no other symptoms. It began at the level of the maxilla, and extended over the mandibu- lar ramus to the neck. No alteration was noted in the overlying skin. A clinical examination showed buccal expansion of the ramus and angle accompanied by a deviation of the mandibular midline to the right. $\mathrm{X}$ - ray examination revealed multilocular radiolucency extending from the root of the extreme distal tooth to the middle ofthe ramus. The lesion was delineated by a very thin bony rim, similar in appearance to that surrounding an ameloblastoma (fig. 22).

Apreoperative biopsy was performed and found to consist of elongated spindle-shaped cells with few mi- loses. Abundant intertwining bundles of collagenaus fibers of varying thickness were predominant, and hyalinization was seen in some areas (fig. 23a-4 The preoperative diagnosis returned was 'semimalignant fibrous tumor ofthe mandible'. In June 1957, an oper- ation was performed under nasal intubation anesthe- sia. The tumor was resected from 
an intraoral ap- proach and the residual cavity was packed with vase- line and iodine-impregnated gauze strips. Intermaxil- lary fixationwas applied. After 9 weeks, the size ofthe 


\section{-...:; -}

$--=$

". $\quad$.:-

C.-

Fig. 23. Typical case of desmoplastic fibroma. a Cell density of the stroma subject to topographic variation. HE. 63 X. b Quiescent and spindle-shaped cells. HE. 100 X. c Cell density is very low. HE. 100 $\mathrm{X}$.

cavity had diminished sufficiently to allow the wound to be packed with Gelfoam and sutured.

The tumor subsequently recurred (fig. 24), infil- trating the masseter muscle (fig. 25), andin June 1961 further surgical treatment became necessary. The le- sion was resected and the right side ofthe distal man- dible was disarticulated to the lower right lateral inci- sor. The biopsy material secured was histologically identical to that obtained when the patient was first admitted in 1957. In 1964, the resected portion of the mandible was reconstructed with autologaus material from the ribs. 
In 1965 , the patient was readmitted, presenting a lesion histologically identical tothat shown in the two previous biopsies. This lesion, located in the anterior edge of the right ascending ramus, was extirpated. 11 years after this operation, no signs of recurrence had been noted. The only residual symptom was anesthe- sia in the right inferior alveolar nerve distribution area. 
Fig. 24. Lateral oblique X-ray of the mandibular angle and ramus showing multilocular areas ofradiolucency. 


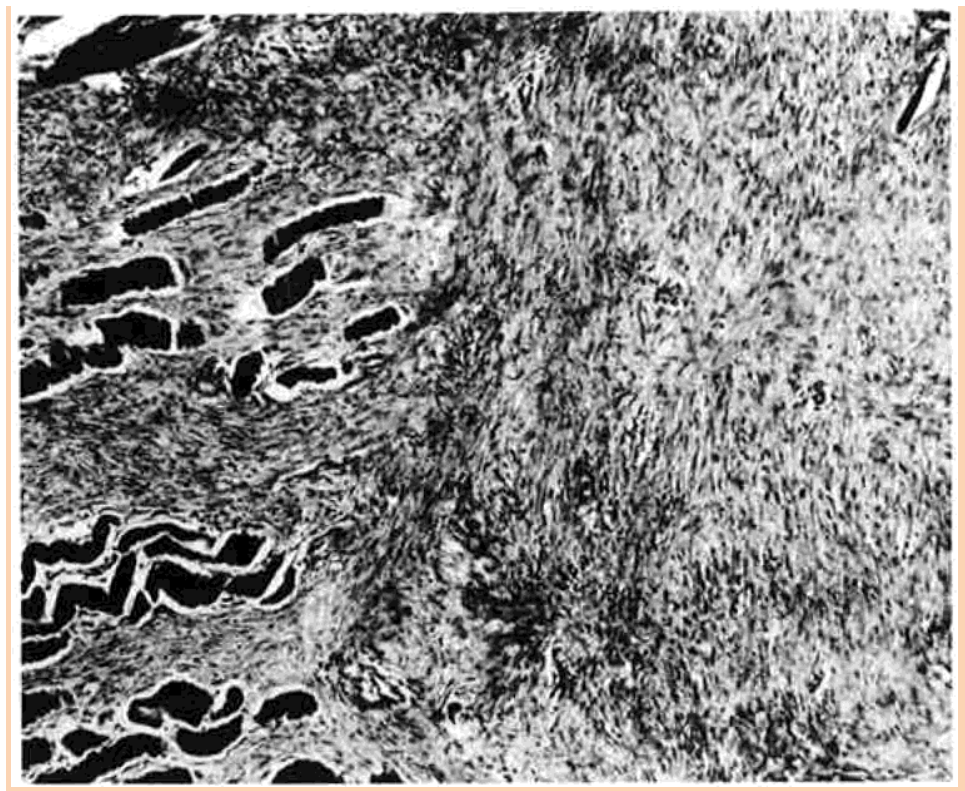

Fig. 25. Desmoplastic fibroma. The masticatory musdes have been infiltrated by fibroblastic tissue. HE.

$65 X$. 
Fig. 26. The cells in this sec- tion of tumor tissue from a case of fibrosarcoma are obviously polymorphous. The size of the nuclei varies and production of finely undulating collagenaus fi- bers is in progress. HE. $400 X$.

Table $\mathrm{V}$ shows a total of 25 known cases;

13 occurred in female patients and 12 in males. The average age is 14 years, though the ages of individual patients in fact range from 1 to 39 years. Overall, table $\mathrm{V}$ suggests that jaw desmoids occur predominantly in young patients. This is in line with Sugiura's [1976] observations on tumors of this type as they occur in other bones.

In only 1 of the 25 cases was the 1esion located in the maxilla, with the posterior regions of the mandibular body, the jaw angle and the ascending ramus being the most commonly affected regions. A hard swelling was found in $88 \%$ of the patients concerned.

3 patients complained of spontaneaus pain and there was only 1 case of pain on palpa- tion. Increased tooth mobility was observed in 4 patients and there were 4 cases of re- stricted buccal aperture. X-ray examinations show an area of radiolucency, generally sur- 
rounded by a well-defined border. In 13 of the 25 cases, the lesion was multi1ocular. Per- foration of the cortex in one or more places, followed by infiltration of the adjacent soft tissue, was common, occurring in 22 cases. Histologica1 examination frequently showed that the adjacent masticatory musdes had also been infiltrated. Confronted with a pseu- do-capsule consisting of peripherally com- pressed cells, the surgeon is discouraged from proceeding radically. Despite its appearance, the lesion is not in fact encapsulated, so that the exact location of its borders cannot be determined macroscopically. This probably accounts for the high recurrence rate found in lesions of this type.

Examination ofthe 25 cases considered in the present study shows that over $30 \%$ of those patients who underwent surgical treat- ment and who were then placed under proper postoperative observation were susceptible 
Fig. 27. Cell-rich areas ofthe tumor tissue in which the collag- enaus fibers are splayed out in various directions. HE. $80 \mathrm{X}$.

to a recurrence of the lesion. It would there- fore seem reasonable to adopt the same re- quirements for desmoplastic fibroma of the jaw as Werner and Schröter [1974] recom- ment in cases of soft tissue desmoid. These authors state that a postoperative recurrence-free period of at last 3 years must elapse before the lesion can be considered to be healed. More than $60 \%$ of those cases described in the literature as free from post- operative recurrence do not meet this requirement.

Peede and Epker [1977] recommend that a

2- to 3-cm margin ofhealthy tissue should be excised together with the tumor to prevent recurrence. Although this results in a much larger bone and soft tissue defect, it would appear to be essential if recurrence is to be prevented. Intraoperative frozen section biopsies, as proposed by Dimakakos et al. [1972] and Peede and Epker [1977], facilitate 
the location ofthe tumor margins, thus mak-

ing a complete eure more certain.

It is interesting to note that in half the cases an erroneous clinical diagnosis was re- turned. The condition was most frequently misdiagnosed as sarcoma, fibrous dysplasia, nonossifying fibroma, odontogenic cyst, in- traosseous hemangioma or ameloblastoma. This is an area in which correct histological diagnosis is especially vital, in view of the dire consequences attendant upon a misdiag- nosis of fibrosarcoma leading to radical abla- tive therapy, particularly when the lesion is found in the young. If misdiagnosed as 'sim- ple fibroma', the surgical treatment then apparently appropriate may result in recur- rence. The majority of these erroneous diag-noses are undoubtedly due to the fact that desmoplastic fibroma and well-differentiated fibrosarcoma are difficult to distinguish from each other histopathologically.

\section{Osseous}

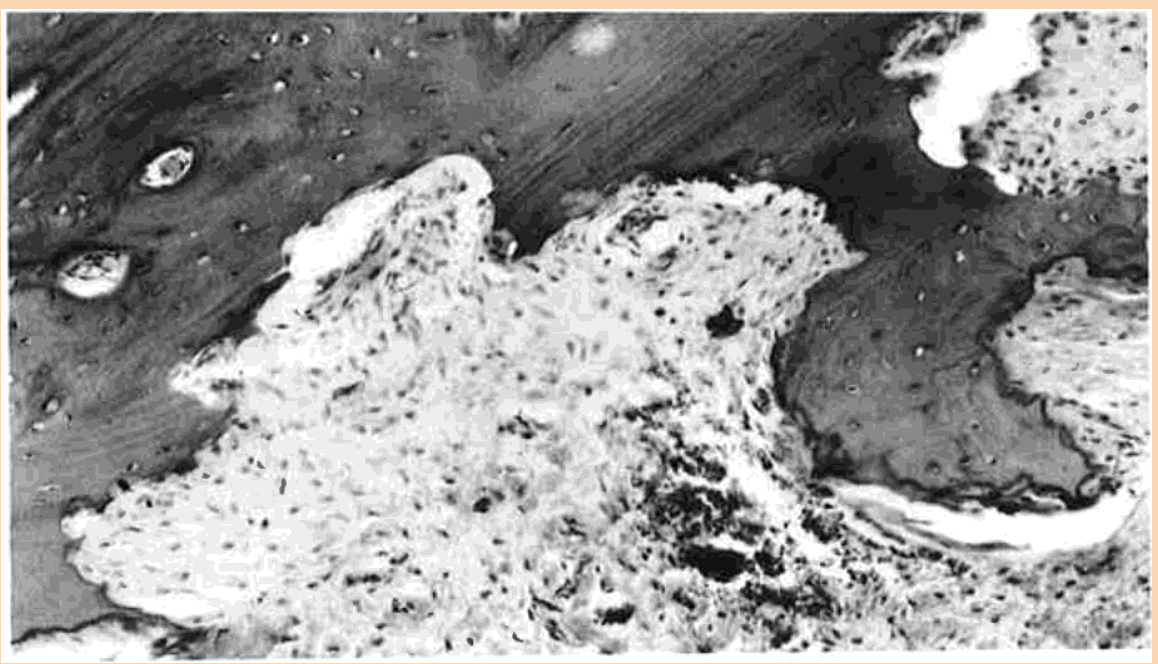

Fig. 28. Peripheral view of a case of desmoplastic fibroma. The lesion is obviously characterized by infiltrative growth. Note the tumor's quiescence and the fact that it contains !arge quantities of collagenaus 
fibersandsmall cell nuclei. Bone resorption is being caused partly by small osteoclasts and partly by direct infiltration. HE. 63 X.

fibrosarcoma is a malignant fibroblastic tumor characterized by varying amounts of collagenaus fiber production and lacking any tendency to form tumoraus bone, osteoid or cartilage, either in its primary site or in its metastases [Huvos, 1979].

Attempts have been made to classify sar- coma according to its grade ofmalignancy, as has been done with carcinoma. Meyerding et al. [1936] evolved a scale using four gra- dations based on a Broders type of classifi- cation. On this scale, types I-IV indicate a progressive increase in cellularity, mitotic ac- tivity and pleomorphism which supposed $1 y$ corresponds to progressive growth and an increase in metastatic potential. Other pa-

Fig. 29. Peripheral areas offibrosarcoma. Note the high cell density, the polymorphaus characteristics of the nuclei and the aggressive way in which the bone tissue is being resorbed. HE. $320 \mathrm{X}$. 
Fig. 30. Section of a fibrosar- coma in which there is an almost complete absence of nuclei. The collagenaus fibers are grouped together in a stellate structure. These characteristics arenot dis- similar to those associated with malignant fibrous histiocytoma. HE. 275X .

thologists prefer the terms 'high grade' and 'low grade sarcoma' which they use to derrote a high or low rate of proliferation and meta- static potential [Stout, 1948]. What makes accurate diagnosis of desmoplastic fibroma difficult is the fact that it can be clinically and radiologically identical to grade I fibrosarco- ma. Well-differentiated fibrosarcoma is char- acterized by abundant collagen and spindly fibroblasts. The nuclei are hyperchromatic (fig. 26) and about twice as densely packedas those of a desmoid tumor (fig. 27-29). Mi- toses may be infrequent, a typical case show- ing one mitosis per two or three power fields

Fig. 31. Typical fibrosarcoma, located in the shaft of the fernur. The bone in the affected area has been dissolved and thin promontories of fine tumor tissue are encroaching upon the contiguous bone. 61year- old male patient (courtesy of Prof. E. Ueh/inger, Zü- rich). 


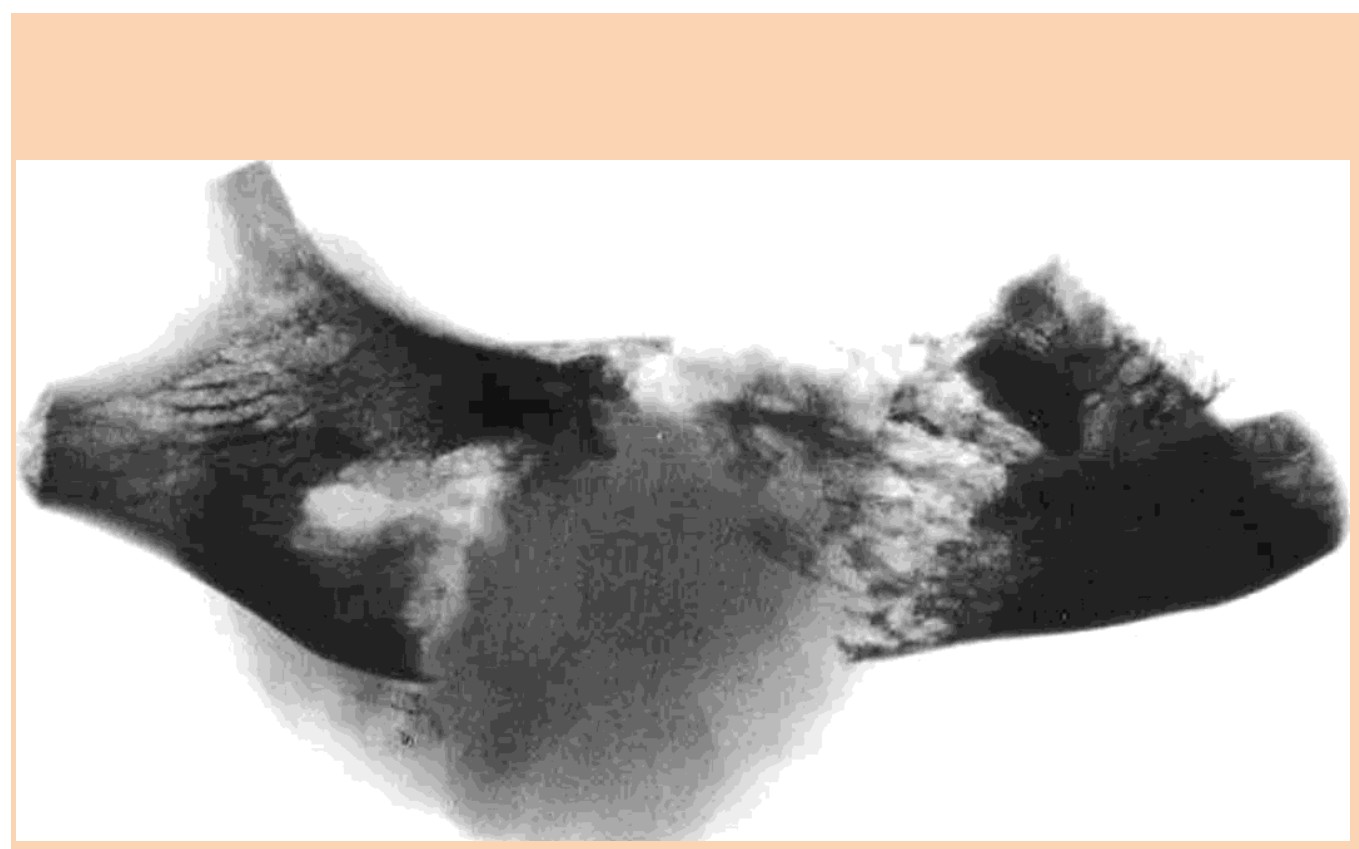

Fig. 32. Macroscopic view of material resected from a 67-year-old female patient with fibrosarcoma of the mandible. Note the pathological fracture (courtesy of Prof. E. Ueh/inger, Zürich).

Fig. 33. Radiological view of the material depicted macroscopically in figure 32 . The pathological fracture and the nonmineralized tumor tissue are both clearly visible.

[Mirra, 1980]. This level of mitosis concentration is greater than that observed in des- 
Table VI. Published cases of central fibrosarcoma of the mandible

doubt as to whether a lesion is in fact desmo- plastic fibroma or fibrosarcoma, numerous sections should be examined so that the pres- ence or absence of atypical nuclei can be established beyond doubt. Only when the absence of atypical nuclei has been con- firmed can a diagnosis of fibrosarcoma be ruled out.

Both low and high grade fibrosarcomas may present foci from which cells veer ofT in a cartwheel or storiform pattern (fig. 30), simi- lar tothat seen in malignant fibrous histiocy- toma [Mirra, 1980]. Typically, medullary fi- brosarcoma is a lytic bone lesion (fig. 31-33), featuring alternate thinning and widening of the cortex. The radiolucent areas which indi- cate hone destruction are often eccentrically located. Since the lesion features no calcifica- tion or bone production, there are no areas of radiodensity. When the lesion occurs in the mandible or maxilla, the clinical symptoms are pain, swelling and loosening ofthe affected tooth. A study ofthe clinical and pathological features offibrosarcoma ofthe mandible car- ried out by Van Blarcom et al. [1971] found that it was characteristic for them tobe an ill- 


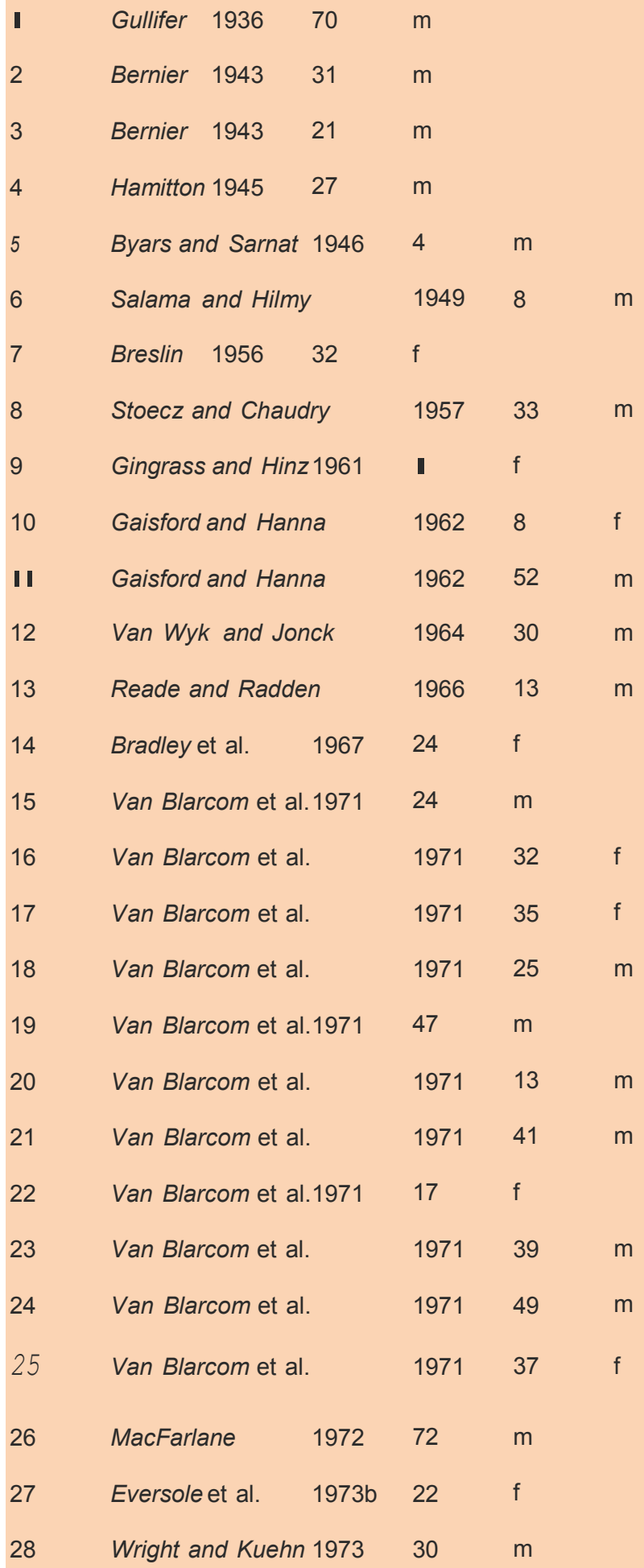




$\begin{array}{llll}29 & \text { Case I Zürich } & 67 & \text { f } \\ 30 & \text { Case 2 Zürich } & 62 & \text { m }\end{array}$

usually smaller than the tumor itself. They suggested that this was probably due to the fact that the peripheral invading portians of the tumor bad not yet destroyed sufficient bone for them to be visible on X-ray. When there were teeth in contact with the tumor, the root surface was frequently found to be eroded. Eversole et al. [1973b] found that $69 \%$ of patients afflicted with peripheral fibrosar-coma survived 5 years or longer, whereas in cases of central fibrosarcoma this was only true of $27 \%$ ofpatients. The lesion apparently 
occurred with equal frequency in either sex, and patients aged between 20 and 39 years seemed to be most commonly affected. Table VI gives details of 30 cases of central fibrosar- coma ofthe mandible.

In closing, it must be emphasized how horrendaus the consequences of misdiagno- sis of lesions of this type can be, and it is to this end, and tothisend only, that the follow-

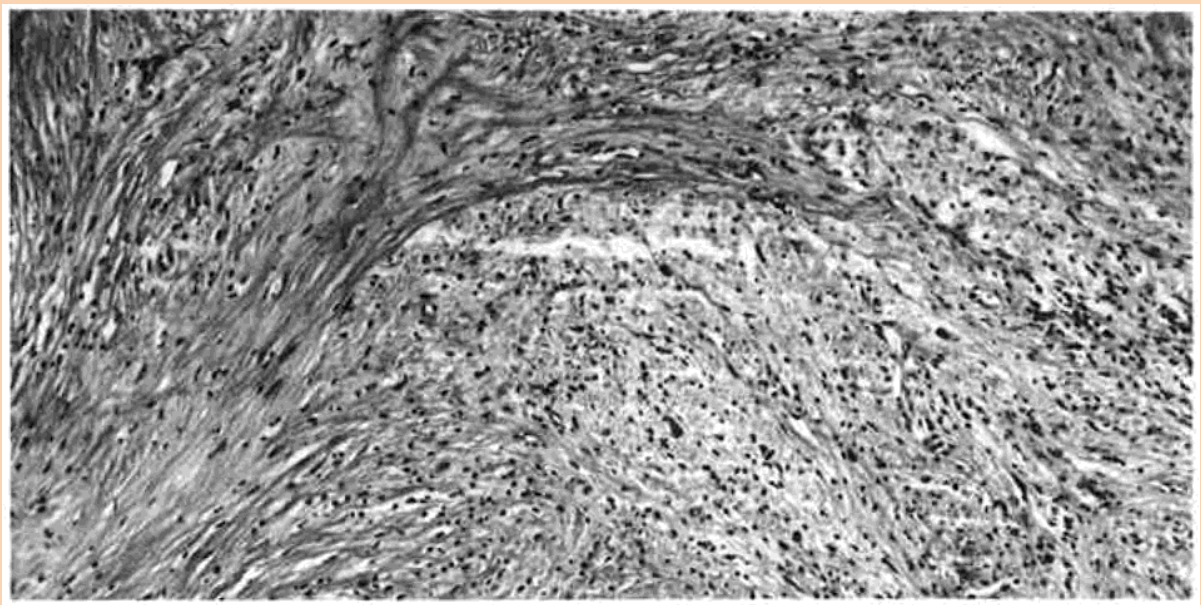




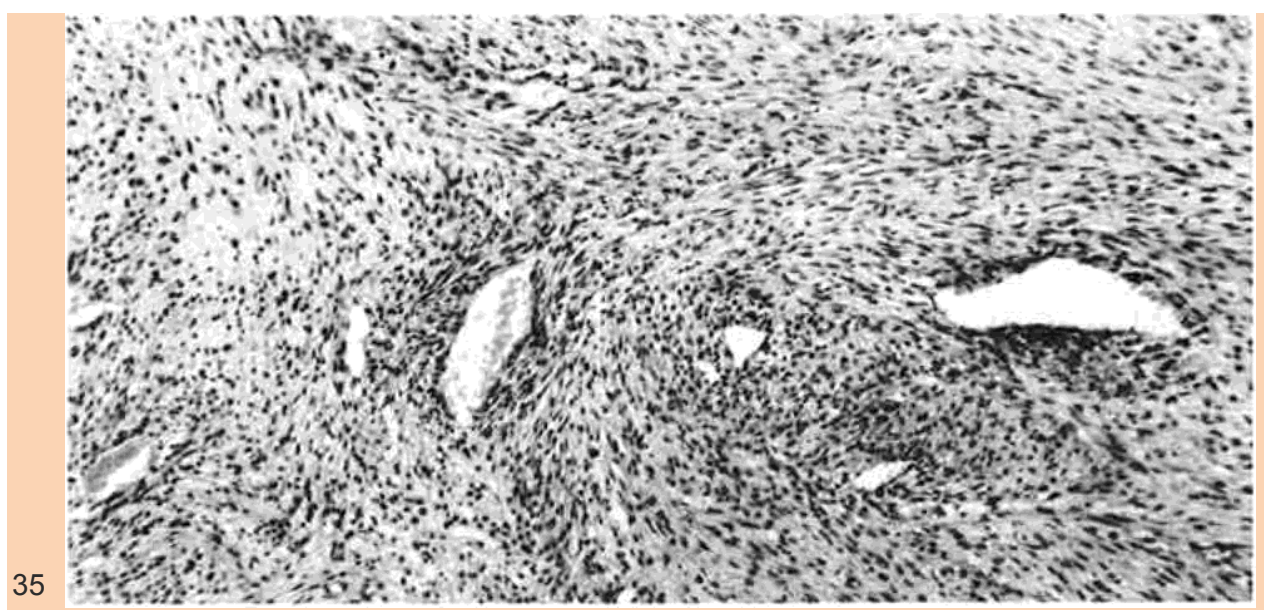


Fig. 37. This figure clearly shows the herring-hone struc- ture formed by the tumor cells. Note the polymorphous charac- teristics of the nuclei and the high rate of collagenaus fiber production. HE. $250 \times$.

ing case is presented. A 33-year-old woman treated at our clinic was cited as a case of 'nasopharyngeal angiofibroma of the mature type (basal fibroid)' occurring in an atypical location [Perko et al., 1969]. From the knowledge currently available, it is imme- diately apparent that the lesion was fibrosar- coma. The material shown here (fig. 34-42) shows the extent of the tragic mistake made at the time, and it is hoped that the pain and suffering the patient underwent in the last 5 years of her foreshortened existence will serve as a warning to the profession as a whole. 
Fig. 34. Apparently harmless tumor tissue in which !arge quantities of collagenaus fibers are being produced. Superficially viewed, the cells would appear to be quiescent. The Jesion was initially diagnosed as angiofibroma of the maxilla (see text). HE. $100 \mathrm{X}$.

Fig. 35. In other parts of the Jesion, the tumor tis-

sue has a higher cell density, particularly in perivascu-

lar areas. HE. $80 \mathrm{X}$.

Fig. 36. In the peripheral areas of the lesion there are areas of very high cell density where the nuclei are noticeably polymorphaus and the tumor cells are ar- ranged in 'herring-bone' structures. HE. $200 \mathrm{X}$. 
Neurofibroma

Neural tumors located centrally in jaw- bones are relatively rare. There is some confusion in the literature as to how benign neural sheath neoplasms should be defined and what terms should be used to describe them. At present, most pathologists differen- tiale between 'neurofibroma' and 'neurilem- moma' (or 'Schwannoma'). Examination of the two lesions under the electron micro- scope shows that while Schwannoma arises from a proliferation of Schwann cells alone, neurofibroma consists of a mixture of Schwann cells and fibroblasts [Lazarus and Trombetta, 1978]. A more recent ultrastruc- tural study by Chen and Mit/er [1979] sug- gests that neurofibroma and Schwannoma have different and distinct origins. Neurofi- broma is a condition apparently originating in the perineural cells, whereas it would seem that Schwannoma arises in the Schwann cells. The authors put forward the hypothesis that Schwann cells might be much better dif- ferentiated than perineural cells and therefore much less prone to neoplastic proliferation. 
Fig. 38. Detail from the pe- riphery of the lesion:The mus- des running across the plate have obviously been infiltrated by tumor tissue. HE. 400 X.

Fig. 39. Biopsy taken 2 years after the first diagnosis of angio- fibroma was returned. The tu- mor tissue is evidently polymor- phous. HE. 400X.

Fig. 40. Aggressive and de- structive tumoraus growth. The bone is being resorbed by multi39 n ucleated osteoclasts. HE. 160 X. 


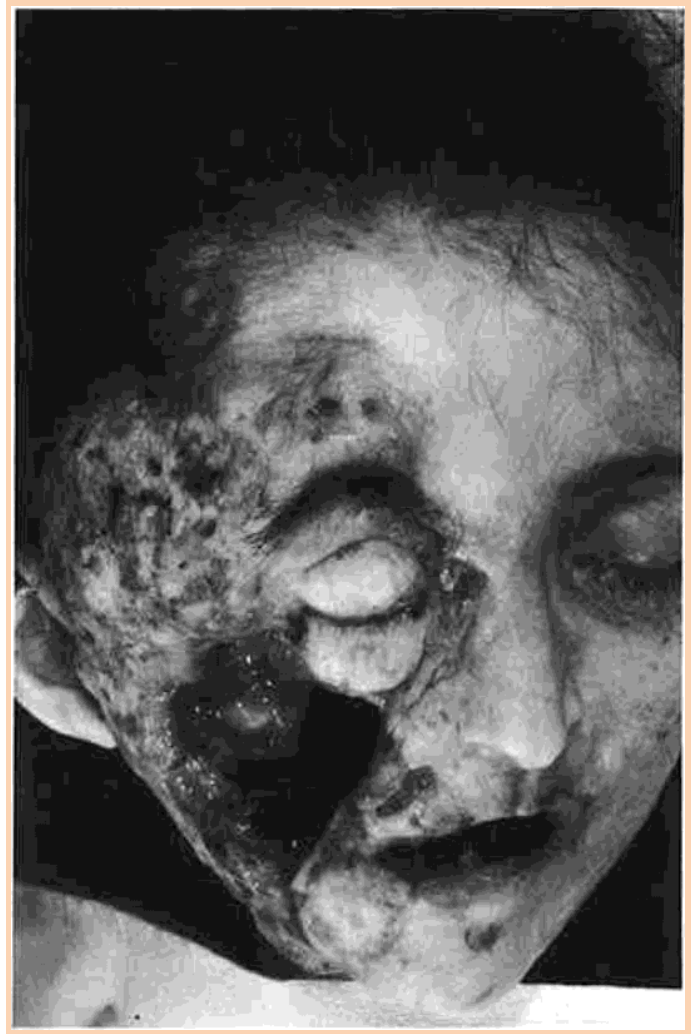


Fig. 41. The tragic state to which the patient was finally reduced. This photograph, taken at the autopsy, shows the immense extent to which the facial bones have been removed or destroyed. Death occurred

5 years after the fi.rst biopsy was taken. The female patient was aged 38 (courtesy of Prof. E. Uehlinger, Zürich).

A study by Prescott and White [1970] de- scribed a new case ofintraosseous neurofibro- ma and reviewed 15 previously published cases.

Ellis et al. [1977] have published an exce1- lent study covering a total of 35 intraosseous benign nerve sheath tumors occurring in the jaws. 23 of these cases were neurofibromas and 12 neurilemmomas. In only 3 of the cases of intraosseous neurofibroma was Recklinghausen's disease diagnosed; 1 of these had multiple tumors affecting both 
Fig. 42. The base ofthe skull shows the infi.ltration of grayish-white tumor tissue in the frontal region.

mandible and maxilla. When neurofibroma occurred in the mandible, there was a definite female predominance (2:1). Neurofibroma was most frequently localized in the posterior section of the mandible, and the majority of patients affected were aged between 10 and 39 years.

Neurofibroma is an unencapsulated neo- plasm containing small nerve fascicles in an unstructured collagenous matrix. The fact that it is not encapsulated means that the tumor can infiltrate contiguous tissues, thus making complete surgical removal difficult [Gnepp and Keyes, 1981]. Most of these 


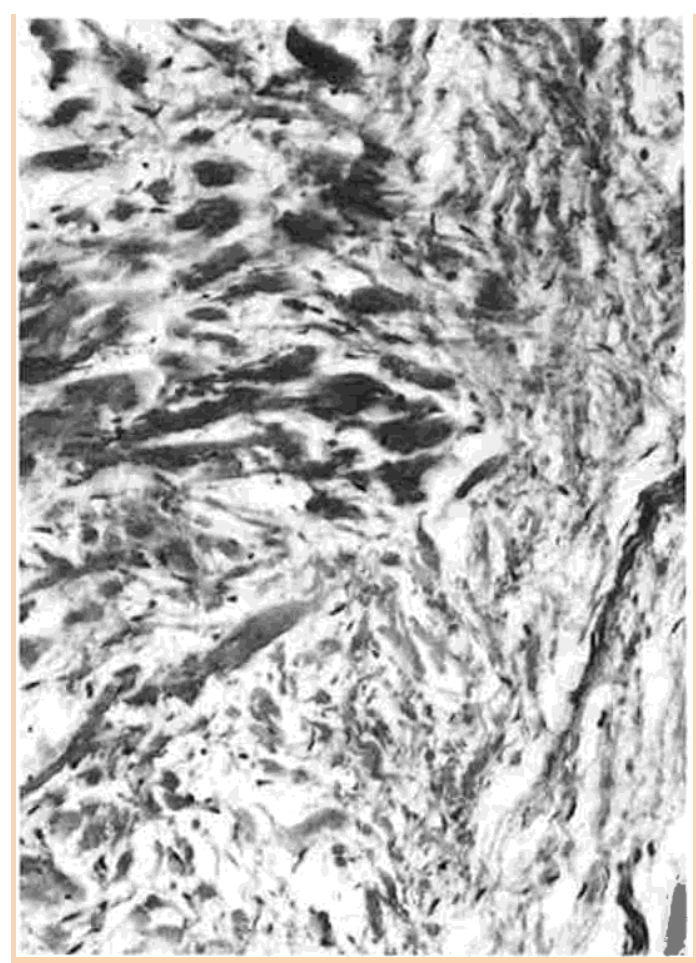

Fig. 47, Detail from figure 46; note the wide ribbons of collagenaus fibers. HE. $100 \mathrm{X}$.

Fig. 43. Tibia of a 7-year-old female patient. The lesion seen is a Recklinghausen's neurofibromatosis, characterized by multiple poorly defined areas of cys- toid radiolucency in the bone tissue.

Fig. 44. Detail from a biopsy taken from a neurofibroma of the mandible, characterized by regressive changes. The condition was wrongly diagnosed as myxoma of the mandible. HE. $160 \mathrm{X}$.

Fig. 45. Neurofibroma ofthe left mandible in a 15- year-old male patient. An area of polycystic radiolucency can be discerned within the bone.

Fig. 46. Cross-section of the first biopsy giving a 
generat histological view. On the basis of this biopsy the condition was initially wrongly diagnosed as des- moplastic fibroma. Small spindle-shaped cells and !arge quantities of collagenaus fibers are the two principal components. HE. $160 \mathrm{X}$. 
Fig. 48. Second biopsy taken from the same lesion. The picture presented is typical of neurofibroma. HE. $80 \times$.

lesions do not have any characteristic radio- logical appearance. Ellis et al. [1977], for example, observed that neurofibroma pre- sented an area of radiolucency which could equally weil be weil or poorly defined, unilo- cular or multilocular (fig. 43). The same au- thors describe neurilemmoma, on the other hand, as tending to present a well-defined unilocular area of radiolucency.

There have been reports ofcases ofneuri- lemmoma which appeared to be multilocular and greatly resembled ameloblastoma [Faw- cett and Dahlin, 1967]. Radiological evidence alone can also suggest that the condition is reparative giant cell granuloma, particularly 
Fig. 49. Typical case ofmyx- oma. The stroma is loose, con- tains few collagenaus fibers and small numbers of stellate cells. HE. 90X.

Fig. 50. Myxoma of the mandible containing numerous foci of collagenaus fibers. HE. $140 \times$.

if it occurs in a young adult [Gutman et al., 1964]. This author's own experience is suita- bly illustrative to be of general interest, since it shows how, when subjected to histological diagnosis, parts of a tumor characterized by regressive alteration can be confused with myxoma (fig. 44). Another 
diagnostic pitfall, namely the way in which desmoplastic fi- broma and neurofibroma can be confused, is also illustrated from personal experience. The presence of bundles of coarse fibrous tis- 
sue induced this author to misdiagnose a neurofibroma of the mandible occurring in a 13-year-old male patient as desmoplastic fi-

broma (fig. 45-47). A second biopsy revealed the presence of structures typically occurring in neurofibroma and the diagnosis was amended accordingly (fig. 48). This second diagnosis was further supported by the fact that all the symptoms of a typical case of Recklinghausen's neurofibromatosis were clinically present.

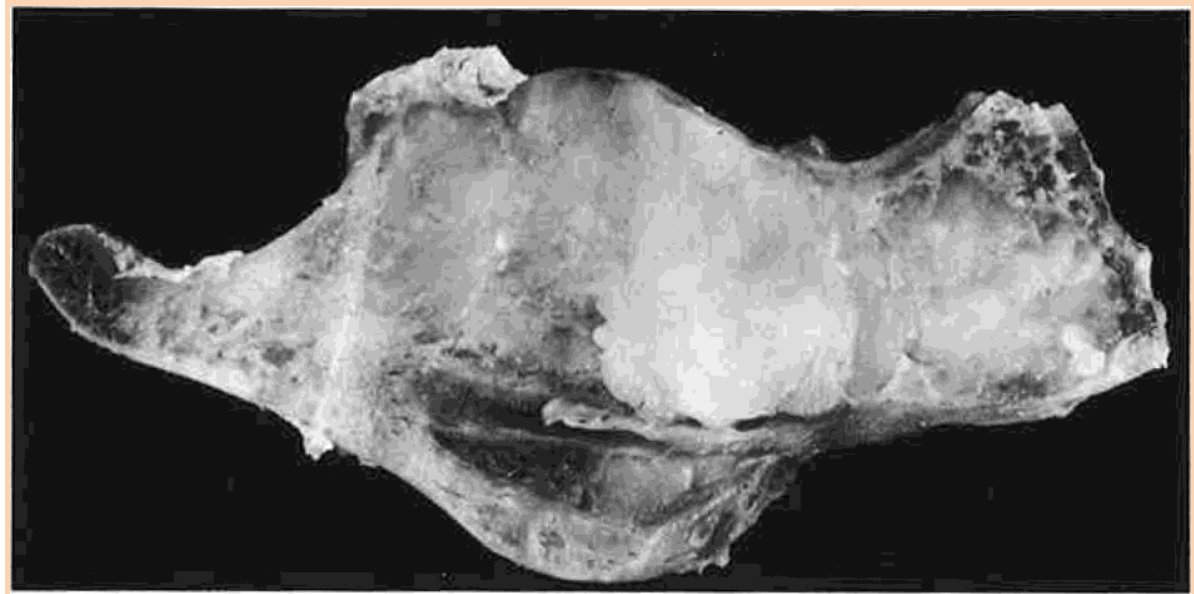

Fig.51. Resected mandible. The lesion seen is a typical case of myxoma (32-year-old male patient).

Myxoma (Fibromyxoma, Myxofibroma)

Current termino!ogy defines myxoma as a tumor resembling primitive embryonie mesenchyme, consisting of well-separated stel- late and spindle-shaped cells in a loose stroma rich in mucopolysaccharides (fig. 49). Fine reticulin fibers course through this 
stroma in all directions. The proportians of myxoid and fibrous connective tissue present vary from case to case. Some myxomas have an abundant fibrous component (fig. 50) and where this is the case they are perhaps more aptly described as myxofibromas [Schmid- seder et al., 1978]. A comprehensive study of myxomatous tumors ofthejaws by Zimmer- man and Dahlin [1958] concludes that these neop1asms are in all probability of odonto- genic origin, since the condition is practically never found in any other bones than those of the jaw. They may, of course, occur in nonosseous tissue. Intramuscular myxoma, for ex- ample, is a well-recognized entity [Stout and Lattes, 1967]. 
Westwood et al. [1974] published a study of myxoma based on ultrastructural evidence. They put forward the view that the fibroblast was the cell initially causing neo- plasms of this type, their hypothesis being that it was fibroblasts which synthesized the abundant mucopolysaccharides found in le- sions ofthistype and giving them their char- acteristic myxoid appearance. Gundlach and Schutz [1977] identified two major types of tumor cells. One resembled a mature fibro- blast, while the other had morphological and functional characteristics which induced these authors to describe it as a 'myxoblast'. Dahlin [1967] states that the incidence of odontogenic myxoma is only one sixth of that of ameloblastoma. Statistical analyses of

!arge numbers of cases of this type, such as that by Davis et al. [1978], have shown that approximately $60 \%$ of the patients affected were aged between 20 and 39 years.

According to the majority of studies, the mandible is more frequently affected than the maxilla [Zimmerman and Dahlin, 1958;

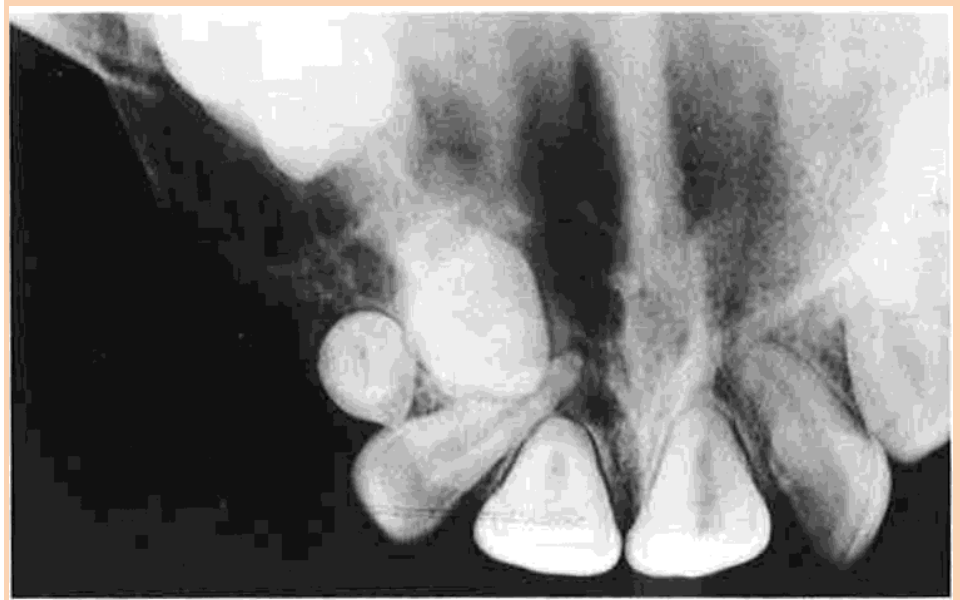


Fig. 52. Mandibular X-ray of a 7-year-old female patient. The myxoma can be seen as a polycystic area of radiolucency within the bone.

Gor/in et al., 1963; Barras et al., 1969; Westwood et al., 1974] (fig. 51). Whitman et al. [1971] published a comprehensive study of the literature then available, which showed that mandibular myxoma most commonly occurred in the posterior man- dibular body, angle and ramus areas, while the anterior portion of the mandible was rarely affected.

Generally speaking, myxomas present no

symptoms and pain occurs only rarely [Davis et al., 1978]. Since myxoma has no consis- tent, radiologically pathognomonic features which allow it tobe distinguished from other odontogenic tumors, histological diagnosis is extremely important in cases of this type.

Tooth displacement is common, and the tumor may also extend the margins thus causing scalloping between the roots. The lesions' radiological characteristics depend on their size and duration. Schmidseder et al. [1978] distinguish between three typical ra- diological pictures. The first variety is the so- 
called 'honeycomb' or 'soap-bubble' type of bone structure. The center of the lesion gen- erally has a delicate, straight trabecular pat- tern, similar in appearance to the strings of a tennis racquet [Kil/ey and Kay, 1964; Lund and Waite, 1966]. The second is character- ized by solitary or multiple cystic lesions, i.e. multilocular structures reminiscent of ada- mantinoma (fig. 52). The third occurs in cases where the tumor has broken through the layer of compact bone and invaded the soft tissue. When this occurs the X-ray may reveal the presence of spicules.

Since recurrence was noted in approxi- mately $25 \%$ of cases [Davis et al., 1978], it is essential that patients be placed under proper postoperative observation. Barras et al. [1969], in a study covering 21 patients, con- cluded that wide resection was the therapy of choice in the majority of cases of this type. Gundlach and Schutz [1977] recommend wide resection followed by primary osteo- plasty. 